Portland State University

PDXScholar

5-13-1975

\title{
The Development of Four English Inflections in the Speech of Educable Mentally Retarded Adolescents
}

\author{
Nancy Barton Richard \\ Portland State University
}

Follow this and additional works at: https://pdxscholar.library.pdx.edu/open_access_etds

Part of the Speech Pathology and Audiology Commons

Let us know how access to this document benefits you.

\section{Recommended Citation}

Richard, Nancy Barton, "The Development of Four English Inflections in the Speech of Educable Mentally Retarded Adolescents" (1975). Dissertations and Theses. Paper 2258.

https://doi.org/10.15760/etd.2255

This Thesis is brought to you for free and open access. It has been accepted for inclusion in Dissertations and Theses by an authorized administrator of PDXScholar. Please contact us if we can make this document more accessible: pdxscholar@pdx.edu. 
AN ABSTRACT OF THE THESIS OF Nancy Barton Richand for the Master of Science in Speech Communication with emphasis in Speech Pathology' Audiology presented May 13, 1975.

Title: The Development of Four English Inflections in the Speech of Educable Mentally Retarded Adolescents.

APPROVED BY MEMBERS OF THE THESIS COMIITEE:

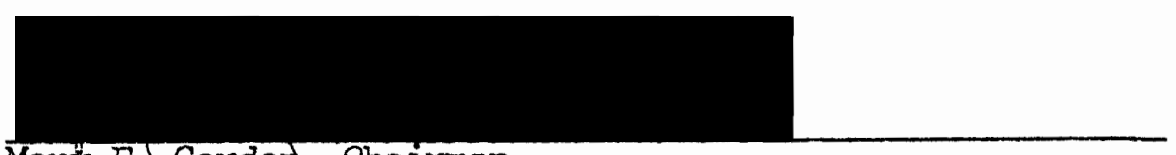

Mary E. Gordon, Chairman
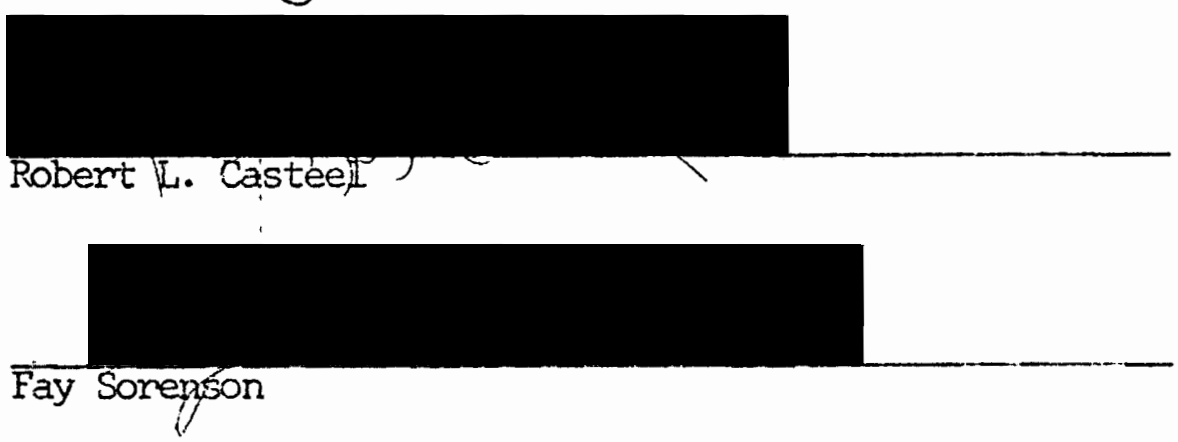

The purpose of this study was to investigate the development and use of certain grammatical morphemes; i.e.; the English inflections for plural, possessive, present progressive and past tense in the speech of educable mentally retarded (EMR) adolescents. The performance on two grarmatical tasks of EMR subjects was compared to that of nomal control subjects matched by mental age scores. The finst task was to produce, veribally, the required inflection for a novel (nonsense) word on a modified version of Berko's Test of English Morphology (BIEM) (Berko, 1958). Secondly, subjects responded to gramma- 
tical contrasts in lexical or real words at levels of imitation, comprehension and production on a modified form of the Imitation, Comprehension and Production Test (ICP) (Fraser, Bellugi and Brown, 1963).

Twenty-four subjects were included in this study. Twelve EMR subjects between the ages of 15 and 20 years were randomly selected from the Vancouver School District. Twelve control subjects with normal intelligence selected from school aged students in regular classrooms were matched by similar mental age to EMR subjects. Mental age was estimated by raw scores obtained with the Peabody Picture Vocabulary Test (Dunn, 1965). All subjects were screened for hearing acuity, articulation and general speech intelligibility.

The results of this study revealed statistically significant poorer performance in the use of English inflections by EMR adolescents when compared with control subjects of similar mental age, specifically in the use of less common allomorphs for plural, possessive and past tense.

Comparisons within each group between performance on the ICP and BIEM did not show statistically significant differences, indicating EMR adolescents as a group use inflections only slightly better in a lexical than in a novel situation. The ICP and BTEM were thus shown to be highly similar instruments, measuring the same variables of linguistic performance. A lack of statistically significant difference was found in the ability of EMR adolescents to imitate, comprehend or produce verbally the required morpheme on the ICP.

No statistically significant difference was found when comparing the performance of the two groups on the ICP, which suggests EMR adoles- 
cents use the four inflections investigated nearly as well in a lexical condition as normal children of a comparable mental age. EMR subjects, however, demonstrated statistically significant poorer performance on the BTEM. Chi-square analysis showed significant differences between groups in the use of less common allomorphs used to inflect plural, possessive and past tense. These findings indicate EMR adolescents have specific difficulties using a particular allomorph, /oz/, to inflect plural and possessive and all allomorphs, /t/, /d/ and $/ a d /$, to inflect past tense.

Patterns of performance within groups were not established due to a limited anount of data provided by the small number of subjects in this study. When the performance of EMR subjects on the BTEM was examined, trends were suggested since all EMR subjects used the inflection for present progressive correctly. Most EMR subjects failed to use a less common allomorph for inflecting plural and possessive and nearly half did not use inflections for past tense correctly. These observations were substantiated by Chi-square analysis between the EMR and control groups.

These results suggest EMR adolescents use most English inflections of the four investigated nearly as well as normal subjects with similar mental ages in a lexical situation. The comparative difficulty of the EMR groups in generating morphological rules governing the use of inflections to a novel condition suggests a limited ability to abstract less well-learned forms to novel situations. These findings tend to support other research in this area which reports the earlier mastery of regular and common allomorphs before the less conmon allomorphs. 
The data reported in this study suggests some qualitative differences, as well as a quantitative delay, in the use of English inflections by EMR adolescents. 
THE DEVELOPMENT OF FOUR ENGLISH INFLECTIONS IN

THE SPEECH OF EDUCABLE MENTALEY

RETARDED ADOLESCENTS

by

NANCY BARTON RICHARD

A thesis submitted in partial fulfillment of the requirements for the degree of

\author{
MASTER OF SCIENCE \\ in \\ SPEECH COMMUNICATION WITH EMPHASIS IN \\ SPEECH PATHOLOGY/AUDIOLOGY
}

Portland State University

1975 
TO THE OFFICE OF GRADUATE SIUDIES AND RESEARCH:

The members of the Committee approve the thesis of Nancy Barton Richard presented May 13, 1975.
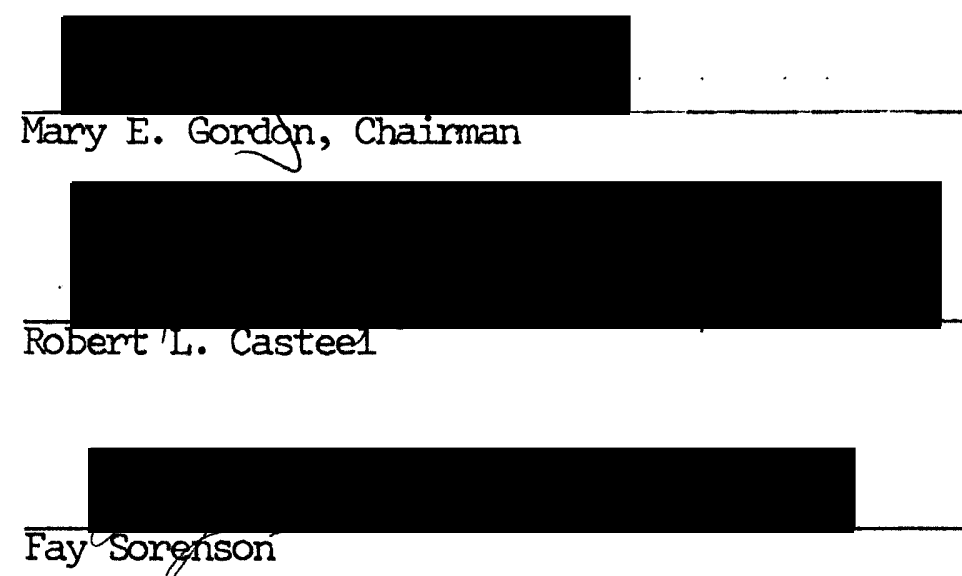

APPROVED:

Ropert Vogelsay, Head, Degartment of Speech Communication

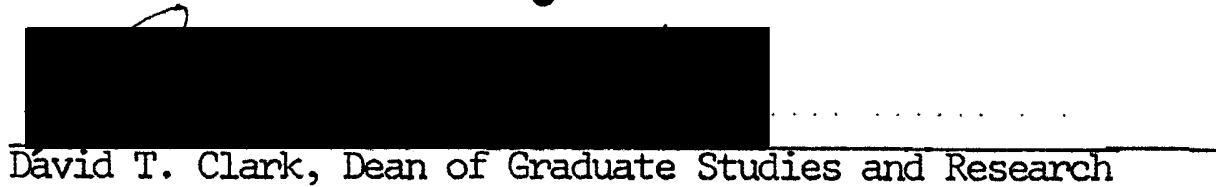




\section{ACKNOWLEDGMENTS}

The completion of a master's thesis is not just the work of the student but also represents the efforts of a great many people. Foremost, are the members of my thesis committee. My personal thanks goes to Mary Gortion, my advisor and chairwoman for her never-ending patience, clear thinking and encouragement. I am indebted to Dr. Robert Casteel for sharing his enthusiasm and knowledge in the area of language development with me. To Dr. Fay Sorenson; thank you for your knowledge and insight. I would also like to thank Dr. Ron Smith for his invaluable help with the statistical analysis.

My gratitude and appreciation goes to Mr. Dick Gjelsteen and the members of the Research Council in the Vancouver School District for their interest and approval which made this study possible. To Dr. Jim Tangeman and Mr. Jim Morrisey, I extend my thanks for finding the experimental subjects for this study.

I would like to thank Dr. Roger Brown for sending the ICP test so quickly.

To Michele, Winfred, Renee, Kathy, Bruce and Phil; thank you for your unselfish assistance.

Finally, I want to thank my family: my mother for her confidence in me, my father who wished for me to continue in school and my husband, Ellis, for his constant support, help and optimism. 
TABIE OF CONIENTS

PAGE

ACKNOWLEDGMENTS . . . . . . . . . . . . . . . . iii

LIST OF TABLES . . . . . . . . . . . . . . . . vi vi

LIST OF FIGURES . . . . . . . . . . . . . . . . . . vii

CHAPTER

I INTRODUCTION . . . . . . . . . . . . . 1

Statement of Purpose ............ 2

Definitions . . . . . . . . . . . . 3

II REVIEW OF THE LITERATURE . . . . . . . . . . 7

Normal Language Development . . . . . . . 7

Biological Basis of Language

Transformational Grammar

Psycholinguistics

English Morphology and Inflections

Acquisition of English Morphemes and Inflections

Language of the Retarded .......... 19

Variables to Consider

Incidence of Comunication Disorders

Features of Retarded Language

Quantitative/Qualitative Theories

Comparative Studies of Morphological

Developrnent

Assessment of Language Skills . . . . . . .

Competence and Performance

Models of Assessment

Berko's Test

Imitation, Comprehension and Production Test

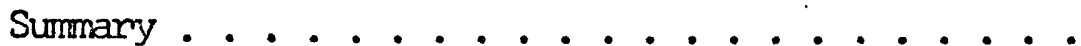


PAGE

III METHODS AND PROCEDURES .............. 35

subjects .............. 35

Instrumentation ........... 38

Test Adninistration .......... 39

Data Analysis .................. 39

IV RESULTS AND DISCUSSION .............. 41

Results .............. 41

Comparisons of Performance Within Groups

Comparisons of Performance Between Groups

Inter- versus Intra- Group Comparisons

Discussion ............. 51

V SUMMARY AND IMPLICATIONS ............... 61

Sumnary ................... 61

Implications ............. 63

Clinical

Research

SEIECTED BIBLIOGRAPHY ................. 66

APPENDIX A ..................................... 71

Imitation, Comprehension and Production Test

Berko's Test of English Morphology

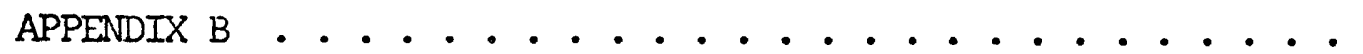

Percent Scores of EMR Subjects on ICP and BTEM

Percent Scores of Controls on ICP and BTEM

APPENDIX C . . . . . . . . . . . . . . . . . . 76

Percent Scores of EMR subjects in Four

Inflection categories on ICP and BTEM 


\section{IIST OF TABLES}

TABLE

PAGE

I Brown's Acquisition Onder for Fourteen Grammatical.

Morphemes and Partial Rank Order of Other

Investigators .............. 21

II Chronological Ages and Raw Scores on PPVT, Form B

for Experimental and Control Group ........ 37

III Mean Chronological. Ages and Mean Raw Scores on PPVT

for Both Groups . . . . . . . . . . . . 37

IV. Comparison of Intertest Performance of EMR

and Control Groups $(\mathrm{N}=12)$. . . . . . . . 42

$\mathrm{V}$ Inter-Comelation of ICP Test components for

Experimental Group $(N=12)$.......... 43

VI Comparison of Mean Scores of EMR and Controls

on ICP and BTEM $(\mathrm{N}=24)$....................... 44

VII Chi Square Values Comparing Performance of EMR

and Control Groups by Combined Inflection

Categories on ICP and BTEM .......... 45

VIII Chi Square Values Comparing EMR and Control Groups

by Performance in Four Inflection Categories

on ICP and BTEM Separately $(\mathrm{N}=24)$....... 46

IX Chi Square Values for Item Comparison between

Groups on the ICP $(\mathrm{N}=24)$.............. 46

X Chi Square Values for ITEA Comparisons by Groups

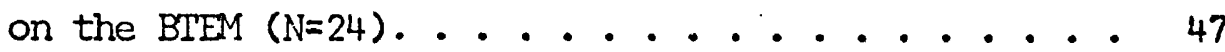




\section{IIST OF FIGURES}

FIGURE

PAGE

1 Order of Acquisition for Fourteen Grammatical

Morphemes in Three Children . . . . . . . 19

2 Numbers of Control and Experimental Subjects

Using Plural Inflection Correctly on ICP

and BTEM ......................... 49

3 Numbers of Subjects in both Groups Using

Possessive Inflection Correctly on ICP

and BTEM ........................ 49

4 Numbers of Subjects Using Inflection for Past

Tense Correctly on ICP and BTEM . . . . . . . 50

5 Numbers of Subjects Using Inflection for

Present Progressive Correctly on ICP

and BTEM ........................ 50

6 Similarities in Mean Scores on ICP and BTEM

Within Groups . . . . . . . . . . . . 53

7 Differences in Mean Scores on ICP and BTEM

Between Groups . . . . . . . . . . . 55

8 Mean Percent Scores for Individual EMR Subjects

in Four Inflection Categories on

ICP and BTEM ................... 60 


\section{CHAPTER I}

\section{INTRODUCTION}

linguistic theory of generative transformational grammar has been the dominant theoretical influence on studies of children's language development in the last decade (Bloom, 1970). Language performance in children has been studied in accordance with the transformational model, the most explicit, comprehensive and systematic form in which adult knowledge of grammar has been represented (Ferguson and Slobin, 1973). Morphology, particularly grammatical morphemes called inflections, has received attention in the literature by Berko (1958), Brown and Berko (1960), Brown and Fraser (1964), Miller and Ervin (1964) and Brown (1965 and 1973). The use of inflections and their order of development has been considered a relatively observable indication of linguistic competence.

Psycholinguistic research has concentrated primarily on children of nommal intelligence, but is now being extended into the language development of mentally retarded populations. Some researchers (Lenneberg, et al., 1964) have reported a quantitative difference or delayed profile in retarded language skills. Other research (Semmel, et al., 1968) suggested the existence of qualitative differences. Comparative studies of subjects at normal and retarded intelligence levels have shown a high degree of variation in data and interpretation. The development of morphology, specifically the use of granmatical morphemes, appears to be both delayed and limited in complexity in 
retarded language. Some authors (Yoder and Miller, 1971) have emphasized the need for further description of the linguistic skills of the retarded.

\section{Statement of Purpose}

The purpose of this study was to investigate the kinds of differences in the development of inflectional morphemes in the speech of educable mentally retarded adolescents. This study compared lexical and non-lexical gramatical performance of educable mentally retarded adolescents to that of subjects with nomal intelligence matched by mental age. The lexical task was to respond to grammatical contrasts in lexicon or real words at the levels of innitation, comprehension and production. The non-lexical task was to produce verbally the required English inflection for novel or nonsense words. The specific questions investigated were:

1. In which tasks do educable mentally retarded adolescents . perform more successfully?

a. Is performance significantly better in the lexical conciition than in the non-lexical one?

b. At what level is performance best: imitation, comprehension or production?

2. Do educable mentally retarded adolescents demonstrate significant differences in thein performance when compared to normal subjects of similar mental ages?

a. Are differences between the two groups significant?

b. Are variations within groups significant?

c. Which difference is greater? 
3. If a cormonality exists in the retanded group, what kinds of responses are most prevalent?

\section{Definitions}

The following definitions are provided in order to clarify the terminology used in this review of the literature. This list is not exhaustive, but these terms are the most common ones appearing in current literature concerning language development.

Allomorph: An allomorph is defined as a positional variant of a particular morpheme by Wardhaugh (1972). The endings of cats, dogs and churches all have the meaning of plural, but differ phonenically (/s/d/ztc/oz/) and are therefore ailomorphs of the plunal morpherne.

Bound Morpheme: A bound morpheme is a morpheme that must occur with at least one other morpheme, for example, the -5 in cats, the -ing in singing and the -duce in reduce (Wandhaugh, 1972). According to Nida (1961), bound morphemes rarely occur in isolation and include prefixes and suffixes.

Competence: Competence is defined as the ability of native speakers to create and to understand grammatical sentences, to detect deviant and ungrammatical sentences and to make other linguistic judgements about utterences in one's native language (Wandhaugh, 1972). Competence is further defined by Slobin (1971) as the "abstract, underlying form of linguistic knowledge." Dale (1972) defined competence as the set of principles that a speaker must have in order to speak the language.

Contentive: Contentives are generally nouns, verbs and adjectives which carry the primary semantic meaning in the sentence. The vast numbers of contentives render this an essentially "open class" (Brown, 1973).

Deep Structure: Deep structure is defined as the abstract structure which is postulated as underlying a sentence, containing the information necessary for both syntactic and semantic interpretation (Wardhaugh, 1972). Phrase structure and base structure are roughly equivalent terms, meaning the rudimentary eiements required for a sentence (Ferguson and Slobin, 1973).

Derivational Morpheme: This term refers to the process by which noninflectional affixes are added to bases to form words, as in en- in enjoin, -ful in hopeful and both dis- and -ful in distrustful (Wardhaugh, 1972). Derivations may change the grammatical class of the 
word (Langaker, 1968).

Free Morpheme: A free morpheme is a linguistic unit that can occur as an independent word, such as cat, judge and happy (Wardhaugh, 1972). Nida (1961) defined free morphemes as those morphemes which may be uttered alone and are always a root word such as boy, girl, and man.

Functor: Functors are chiefly inflectional morphemes, articles and the copula. Functors represent a relatively closed class of words as contrasted to contentives and are less important to meaning (Brown, 1973).

Generative Transformational Grammar: Generative grammar or transformational grammar is a grarmar that generates sentences, assigns structural descriptions to these sentences and relates deep structures to the surface structure and sounds in a particular language (Wardhaugh, 1972). A generative grammar is also defined as a system of rules that derive an infinite set of well-formed sentences and assigns them correct structural descriptions (Ferguson and Slobin, 1973). The terms generative grammar and transformational grammar are used interchangeably throughout the literature.

Inflectional Morphemes: Inflectional morphemes are affixes, usually suffixes in English, that change the form of a word without changing it's grammatical class or basic meaning. Nouns and verbs may be inflected for plural, possessive, past tense or present progressive tense (Wardhaugh, 1972).

Levels of Language: Levels of language refers to three aspects of linguistic performance: imitation, comprehension and production or expression. These aspects of linguitic performance with regand to assessment models are discussed by Brown (1973), Carrow (1971) and Rosenberg (1970).

Lexicon: Lexicon is defined by Wardhaugh (1972) as the vocabulary of a language. Langaker (1968) further defined the lexicon as the inventory of morphemes and their possible combinations to form more complex lexical items.

Mompheme: A morpheme is generally defined as the minimal unit of meaning. Cats contains two such units, unwisely, three (Wardhaugh 1972). Langaker (1968) stated the morpheme is the minimal unit of gramatical structure with a fairly clear and consistant meaning.

Morphology: Morphology is briefly defined by Nida (1961) as the study of morphemes and their arrangements in forming words. Carroll (1967) stated that morphology is the listing of words and meaningful forms of language and the specification of the ways these forms may be modified when placed in various contexts.

Morphophonemics: Brown (1965) stated the inter-dependence of morphology and phonology create an area between the two, morphophonemics. Morphemes follow certain phonological rules of occurrence in speech. 
Morphophonemic rules are needed to bring the composite sentence to a recognizable form at the surface level in a sentence.

Performance: Actual linguistic Dehavior on the translation of knowledge or competence into action is called performance (Dale, 1972). Performance may not accurately represent competence due to the interference of psychological and physiological factors such as age, fatigue or tension (Slobin, 1971).

Phonology: Phonology is defined as the specification of units of sound which compose words and other forms in language (Carroll, 1967).

Psycholinguistics: Psycholinguistics is defined by Wardhaugh (1972) as the study of the inter-relationships of psychological and linguistic behavior. The application of transformational grammar to the study of language development in children has become known as psycholinguistics. Slobin (1.971) wrote: "Psycholinguistics brings together the theoretical and empirical tools of both psychology and linguistics to study the mental processes underlying the acquisition and use of language."

Semantics: Semantics is generally defined as the specification of the meanings of linguistic forms and the syntactical patterns in relation to objects, events, processes, attributes and relationships in linguistic experience (Carroll, 1967).

Surface Structure: Surface structure, as distinguished from deep structure, is the superficial, phonetically represented utterance paired with semantic interpretations and syntactic order. The mediation between deep and surface structures is accomplished through abstract structures generated by the syntactic component of grammar (Slobin, 1971). In other words, the deep structure is represented by abstract, syntactic strings which become phonetically represented at the surface level as phonetic strings--the actual utterance heard. Similarly, surface structure is described by Wardhaugh (1972) as the gramatical relationships among the words of an actually uttered or observed sentence.

Syntax: Generally, syntax is defined as the set of principles for combining words to form grammatical sentences (Langaker, 1968). The concept of syntax has been expanded in the transformational grarmar framework and is defined by Camoll (1967) as the specification of patterms in which linguistic forms may be armanged and of the ways in which these patterns may be modified or transformed in varying contexts. Syntax operates on two levels. At the surface level, syntax is related to the ordering of morphemes and the phonological structure of a sentence. At the deep level, syntax is related to semantic interpretation (Slobin, 1971).

Transformational Rules: Transformational rules serve to ultimately derive the surface string yielding an observable utterance. These rules map such underlying strings into newly structured strings that 
are progressively closer to actual sentences. They delete, permute, add or subtract elements in these strings (Ferguson and Slobin, 1973). 
CHAPTER II

\section{REVIEW OF THE LITERATURE}

Recent studies of language development have centered around the theories of generative transformational grammar. The combination of linguistic theory and psychological considerations of language behavior has become known as psycholinguistics. Researchers such as Brown and Bellugi (1964), Miller and Ervin (1964), Klima and Bellugi (1966), Menyuk (1969) and Brown (1973) have contributed great quantities of data through longitudinal studies of English speaking children. The interpretations of their data and that of other researchers in this field have begun to reshape traditional concepts of language development.

\section{Normal Language Development}

Transformational grammar provides a model for research in language development. The general features of this model will be reviewed briefly in this section, with particular emphasis on the development of morphology, specifically inflections. Nida (1961) has stated that no part of language can be adequately described without reference to all other parts. For this reason, general theoretical background will be considered first.

Biological Easis of Language

It is generally assumed humans possess specific capacities 
for language which other species do not. Human language, apart from cormunication systems of other species, was defined by Carroll (1967):

A language is a structured system of arbitrary vocal sounds and sequences of sounds which is used, or can be used, in interpersonal communication by an aggregation of human beings and which rather exhaustively catalogs the things, events and processes in the human environment.

The development of the human brain is the primary biological prerequisite for Man's unique language capacity (Menyuk, 1971). Lenneberg (1967) has written extensively about maturation and the development of the brain as correlated processes in the development of language. He concluded that it is not possible to assign any specific neuro-anatomic structure to the capacity for language, but that it is most probably due to the peculiar way the various parts of the brain work together. Menyuk (1971) concluded similarly that Man's unique capacity to acquire language is related to the functioning of his brain and the comparatively long period of maturation.

Human physiological capacities and restrictions are thought to be related to language skills. Physical matumation and language development have been correlated by Lenneberg (in Menyuk, 1971). The developmental process of language acquisition, motor coordination and cognition have generally been characterized as a continuing "differentiation" as the child becomes more adept in all areas (Menyruk, 1971, and Hopper and Naremore, 1973).

The biological basis for langlage, as discussed above, has been further extended to suggest Man has an "innate capacity" for language which other species cio not. MeNeill (1971) presented the basic grammatical relations of nouns and verbs in early child language as evi- 
dence of an innate capacity for language. Generally then, a basic postulate of generative transformational grammar is that the human is born with certain physiological and psychological capacities which lay the foundation for species-specific language skills.

Generative Transformational Grammar

Transformational grammar was defined by MoNeill (1966) as a distinction between the superficial and underlying structures of a sentence. The adult speaker of English, for example, performs "transformations" on his pre-verbal thoughts in order to derive an utterance. Chomsky (1971) discussed the underlying structures of an utterance or sentence as being abstract linguistic information. The process of deriving an utterance from abstract linguistic information or deep structures is then the application of changes or transformational rules. Transformational rules specify in what ways the basic sentence patterns can be transformed and in what order the rules are to be applied (Carroll, 1967). Chomsky stated that transformational operations are exceedingly complex and can be shown in "a fairly complex, but reasonably natural algebra."

There are several levels preceding the sentence. The first is an abstract thought, followed by basic gramatical units, underlying strings, the kernel sentence and finally the surface structure or actual sentence (Chomsky, 1971). Transformational mules relate the deep and surface levels, allowing the speaker to generate an infinite number of sentences from a finite set of basic of units (McNeill, 1966). The transformational model is based on a process of generative grammar. The speaker-listener 
compares input signals with basic grammatical units of syntax, semantics, morphology and phonolgy (Chomsky, 1971). The knowledge that humans possess to accomplish this evaluational procedure has been called "competence" (Chomsky, 1971 and McNeill, 1966). The application of competence is called "performance". Performance can operate at three levels of language: imitation, comprehension and production.

Generative transformational grarmar has incorporated the terminology of more traditional structural linguistics to describe language performance. Syntax, semantics, morphology and phonology are included in performance (Ruder, 1972). The syntactic component of Chomsky's generative grammar has four levels: phrase-structure rules, lexical sub-catagorization rules, transformational rules and morphophonemic rules (Cazden 1973). An example of the application of these foum levels in operation is provided in the literature by Brown and Cazden (1973).

From extensive sampling of utterances made by Adam, two years of age, Brown and Cazden (1973) wrote a grammar for him. According to Adam's grammar, a possible utterance, "Where those dogs goed?" was constructed, The important rules required to derive this utterance will be briefly discussed in this section in order to illustrate the four levels of the syntactic component of transformational gramman listed above. The importance of the following discussion will be to demonstrate the complexity in the language of a two year old. The deep and surface structures of Adam's utterance are mediated by the changes made according to certain mules. The interaction of derivational rules and their complexity are especially important to consider when comparing 
the language of normally developing children to mentaliy retarded individuals.

In onder to derive the surface structure of the utterance, "Where those dogs goed?," a set of rules is required which are part of the syntactic component of generative transformational grammar. Initially, at the deep structure level, phrase structure rules are applied to code the utterance into nominal and predicate and a string of abstract symbols for what will become a string of morphemes. Morphemes are symbolized as imp (imperative) wh (wh-question) and neg (negative). The formula shown below represents the germs from which the imperative, interrogatives and negatives can be developed. According to transformational grammar, fourteen phrase structure rules are applied to derive the string of abstract symbols for morphemes below: $\rightarrow$ means: "may be re-written as")

\section{Sentence (imp/wh) + neg Nominal + predicate.}

From the first phrase structure string show above, a new string is derived as the next step. Instead of the actual words in the sentence the new string contains symbols for lexical categories (parts of speech) to which the symbols belong. The lexical categories are symbolized below as NP (noun phrase) Det (determiner) and N (noun) which is further elaborated into a string of abstract symbols representing parts of speech: wh (implying question), Det (determiner), N,(noun), past indicating past tense), $\mathrm{V}$ (indicating verb) and somewhere (symbolizing preposition). These are shown below:

2. $\mathrm{NP} \rightarrow$ (Det) $+\mathrm{N} \rightarrow$ wh--Det--N--past--V--somewhere.

From the phrase structure level, Adam's utterance moves to the subcategorization level where lexical category symbols shown above are replaced by appropriate lexical items which are closer to the words heard by the speaker/listener. The lexical items substituted for phrase 
structure symbols are shown below:

3. (Wh)-those-dog-(Past)-go-somewinere.

The steps discussed above are the essential ones for a base or deep structure for Adam's utterance. From the point of a lexical string, as in 3. above, transformational rules are applied to further direct the pathways of change required for surface strings. Twenty-four transformational rules are said to be required in Adam's utterance (Brown and Cazden, 1973). Only two important trassformations will be discussed here. The important transformations used in this utterance are the incorponation of wh and somewhere and the affixation of the past to the main verb (MV) "go". These two transformational rules are illustrated below as mule numbers XIV and XIX.

4. XIV. wh incorporation for MV sentences:

wh--Nominal--Venb (Nominal)--somewhere implies wh + somewhere wis + scmewhere-Nominal--Verb (Nominal)

Sentence $\rightarrow$ h + somewhere--those dogs--(Past)--go. XIX. Affixation of Past:

$x^{1}-$ (Past) aux $-V-x^{2}$ jmplies $x^{1}--V=$ Past $-x^{2}$

( $x^{1}$ and $x^{2}$ simply stand for any other sentence constituents)

Sentence $\rightarrow$ wh + sornewiere--those-dog--go + past

The final stage in the derivation of Adam's uttenance involves the application of phonological mules at the morphophonemic level as the composite sentence is brought to a recognizabie form. Three morphophonemic males are required to derive the word "where" from the symbols wh + somewhere, "goed" from symbols go + past and to plimalize dog to dogs. The application of these rules is shown below: 
5. wh + somewhere $\rightarrow$ where

$$
\begin{aligned}
& \text { Verb (go }+ \text { Past } \rightarrow \text { go }+ \text { ed (goed) } \\
& \text { Noun }+ \text { Plumal } \rightarrow \text { dog }+s \text { (dogs) } \\
& \text { Senterce } \rightarrow \text { Where those dogs goed? }
\end{aligned}
$$

In this example the second rule is an erroneous form of the past morphophonemic rule for "go" which is: Verb (go) + Past $\rightarrow$ went.

The importance of the discussion of deep and surface strings in this section was to dennonstrate the theoretical components of transformational gramman in operation. It can be seen in the derivation of Adam's utterance that each component is dependent upon the other i.e., transformational rules change phrase structure strings which are further modified using phonological and morphological mules. Rather than separate entites, rules of phonology and morphology are encompassed in transformational gramman as the observable components of an interlocking system.

\section{Psycholinguistics}

The application of the transformational model to the study of child language development must depend on performance aspects as primary data. Competence is then inferred from empirical data (Chapnan, 1971). Psycholinguistics, then, combines the theory of genenative granman with the tools of descriptive linguistics. Carroll (1967) has outlined the linguistic conponents necessary for the study of language development; syntax, semantics, morphology and phonology, as defined earlier in this paper. 
When studying the child's linguistic behavion, his competence level is inferred from his performance (Ruder, 1972). The acquisition of certain linguistic skills is analyzed in order to determine the stage of development (Klina and Bellugi, 1966). As he progressively becones a more sophisticated language user, the child approximates adult gramiar. It is generally stated in the literature that children have acquired majon grammatical patterns by the age of six years (Carroll, 1967).

The appearance of transformations in children's speech has been studied extensively by Menyilk (I969). She concluded that children's language develops through a process of greater and greater differentiation. She found that children may over-generalize a regular grammatical rule and be gramaticaily incorrect. The energence of the regular past terse inflection and its indiscriminate use is one example. Cazden (1973) also suggested that inappropriate inflections such as "goed" can result from missing or inadequate transfomational rules which govern the additions and deletion of senantic units. Whatever the basis of children's "errors", the cycle of over-generalizations and further diffenentiation has been repeatedly observed in children's language. This cycle is thought to be an integral part of increasirg gramnatical mastery in children (kjopper and Naremoore, 1973).

English Morpioicgy and Inflections

Linguistic behavion, indicating the knowledge of rules, has been studied widely by many researchers in the ficld of psycholinguisitcs. 
Specific rule behavior, that of morphological inflections, has been investigated by Berko (1958), Miller and Ervin (1964), Klina and Bellugi (1966), Brown, and Cazden (1973), Anisfeld and Tucken (1973), Cazden (1973) and DeVilliers and DeVilliers (1973). Before discussing the findings of the above authors, it is important to discuss concept of "rule" behavion and specific morphological rules called inflections.

Slobin (1971) has emphasized the difficulty of rules as evidenced in linguistic behavior. He pointed out the word "rule" unfortunately implies that explicit rules of granmar are acquired by children. Rather than explicit rules of grammer, the present concept of rules is used in relationship to behavioral evidence, when an individual "acts as if he knew a rule." Clearly, most individuals would fail to be able to state the explicit rule he is using at a specified point in his language. The earliest sort of evidence that some sort of rule exists in child language is found in regularities of behavior. Ervin-Tripp stated (in Slobin, 1971), "To qualify as a native speaker, one must learn. . . rules. . . This is of course, that one must learn to behave as though one knew the mules."

Brown (1965) categorized morphemes as "free" and "bound" forms. Free morphemes such as "run" and "be" are meaningful units that can stand alone in language. Bound morphemes cannot stand alone, but modify the meaning of morphemes as an "inflection or derivation." Inflectional morphemes such as $/ \mathrm{s} /, / \mathrm{J} /, / \mathrm{t} /$ and $/ \mathrm{d} /$ no not change the words they modify. It is the bound inflectional morphemes which 
the child must learn to form past, present progressive, plural and possessive formis in English. These morphemes have phonemic variations called "ailomorphs". For example, the regular plural /s/ and Izl are two allomorphs of the same morpheme. In other words, inflectional morphemes follow certain phorological mules of occurrence in speech, e.g., the regular plural /s/ only occurs after certain phonemes to inflect plurality. Brown (1965) stated that the interdependence of morphology and phonology create an area between the two called "norphophonemics". This relationship between morphology and phonology has been described as a difference in the level of structure by Langaker (1968). He described morphology as the underlying representation of meaning and phonology as the surface structure rules applied to the more abstract morphemes.

More recentiy, Brown (1973) has differentiated between the morphemes in language using traditional linguistic terminology, "functors" and contentives". Brown suggested "grammatical morphemes" exist as a separate class and they are equivalent to functors in language. Grammatical morphemes or functors are said to play a less than essential role in language when compared to contentives. Rather than provide the semantic information as contentives do, they serve to modulate meaning. The following quotation from Brown (1973) more exactly expresses his concept of grammatical morphenes:

Still, I and others feel that there is sone difference in the meanings of reference making contentives and most grammatical morphemes. Some of the latter seem to "tune" or "modulate" the meanings associated with the contentives in the sense that the modulation is inconcejvable without the more basic meanings. Thus $a$ and the made the thing referred to by $a$ 
noun specific or non-specific. The present progressive -ing indicates that a process named by a verb is in progress at the time of speaking. The past inflection indicates that a process named by $a$ verb began and ended before the time of speaking. The plural inflection indicates that the thing referred to by a noun exists in more than one instance. It does not seem possible to thinik of these tunings of modulations without the things and processes they tune whereas it does seem possible to conceive of the latter without the former.

Inflectional morphemes then, serve to clarify meaning through their role in changing verb tense, pluralizing and further modifying the contentives in language.

Acquisition of English Inflectional Morphemes

The pattern of acquisition of English inflections has been observed by Berko (1958) to be one of "consistency, regularity, simplicity." In her study of morphological development in 4 to 7 year old children, she found that the children progressed consistently in their ability to apply morphological inflections to nonsense words. When comparing younger and older children, Berko found significant improvement in the performance of plural and present progressive verb tense with age.

Berko's technique of inflecting nonsense stimuli has been used repeatedly in studies of morphological development. Millen and Ervin (1564) presented data that suggested a time span between the ability to inflect lexical words as opposed to nonsense words or novel words. There was a small, but reliable, gap of two weeks between the time when the children contrasted blosk and blocks and the time when they contrasted the nonsense words bik and biks. For other inflectional morphemes, the time gap was greater. Generally, Miller and Ervin 
found that children were able to form plunals with novel or nonsense words between the ages of 2 and 3 .

Other studies of the acquisition of inflectional morphemes have shown general agreement with regand to the onder of development, although children progress unevenly in their mastery over morphological and phonological rules when age is considered (Foley and Locke, 1971, and Brown, 1973). In their analysis of the spontaneous speech of children between 1.3 and 3.3 years, Devilliers and DeVilliers (1973) reported, "The children produce longer and longer sentences and add basic grarmatical morphemes. . . The order in which they do this showed a remarkable degree of invariance." These authors also suggested grammatical and semantic complexity affected the order of morphological acquisition. Generally, it appears that a combination of factors in the child's ability to receive and perceive verbal stimuli contributes to the appeanance of inflections in his speech.

In his work, Brown (1973) reported his and other studies of fourteen grammatical morphemes and their order of acquisition. The grammatical morphemes selected by Brown included inflectional morphemes; acquisition of these morphemes was based on a 90 percent criterion. His findings are displayed in Figure 1 . The onder of morphene acquisition for Adam, Eve and Sarah are arranged from top to bottom, representing early to later acquisition. The spacing of names relative to Stages I-V and to one another represent the time spacing in points of age. Stages are defined by Brown in morpheme Mean Length of Utterance values (MUU): 


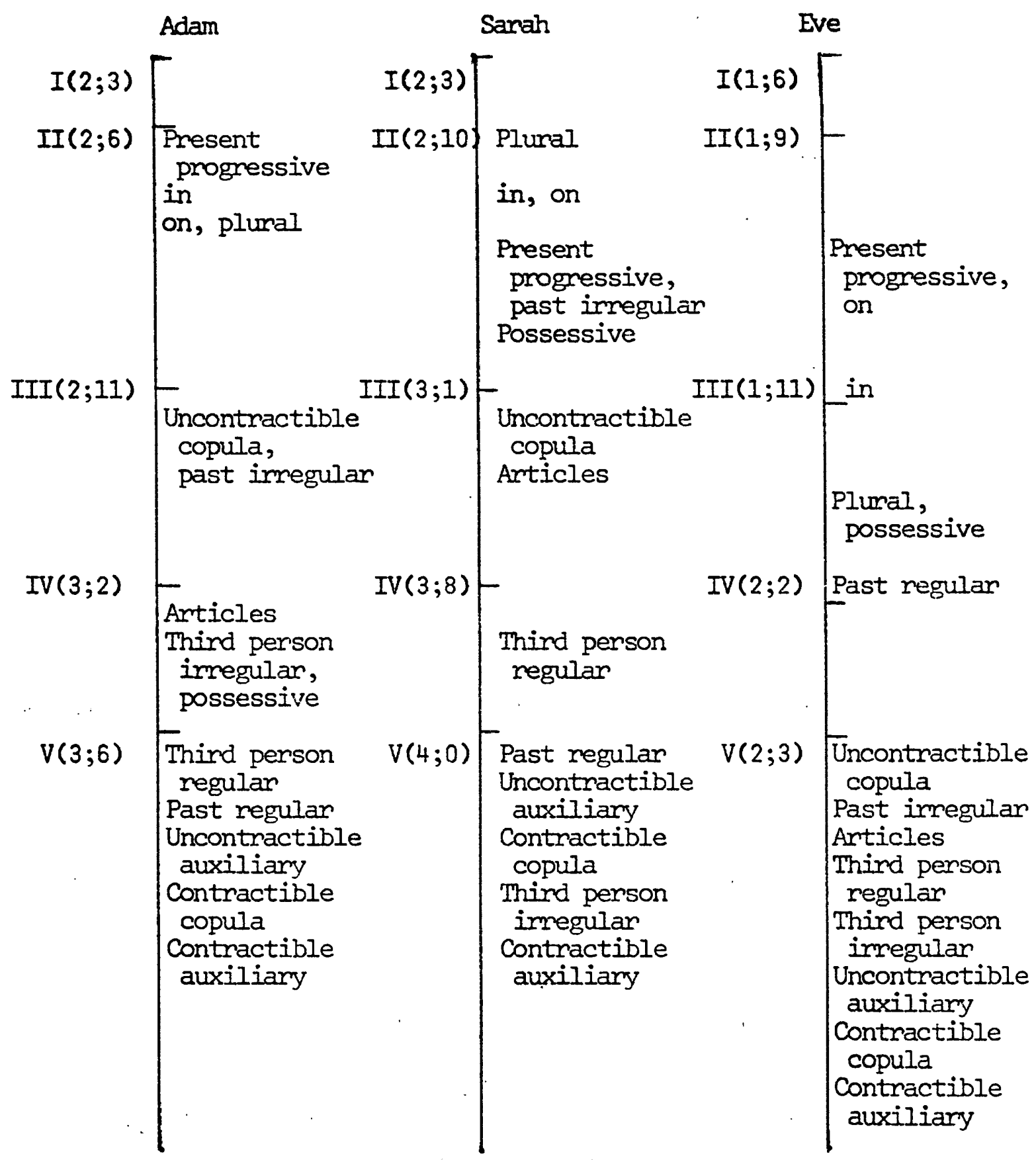

Figure 1: Order of Acquisition for Fourteen Grammatical Morphemes in Three Children Reported by Brown (1973) 
Stage I- $\quad 1.75 \mathrm{MLU}$

Stage II- $2.25 \mathrm{MLU}$

Stage III- $2.75 \mathrm{MLU}$

Stage IV- $3.50 \mathrm{MLU}$

Stage V- $4.00 \mathrm{MIU}$

Based upon this study, Brown concluded the developmental onder of fourteen grammatical morphemes was amazingly constant across three unacquainted American children. Cazden (1973) presented similar data in her study of inflections in the speech of these same three subjects used by Brown. She established a continuum of development for five inflections: plural, possessive, present progressive, present indicative and past tense. Cazden observed a pattern of no use, followed by infrequent but correct use, followed by over-generalization of the particular form. She interpreted this occurrance as a function of the continuous development of gramatical competence in children.

As mentioned before, Brown (1973) reported an overwhelming genemality in the order of acquisition for fourteen gramnatical morphemes. Table I summarizes all of the studies he reviewed. In a given column, mumbers appear just opposite those morphemes which are developmentally ondered with respect to one another by data or summary statements. Considering that different criteria of acquisition were used in every study represented, the broad agreement among studies can be said to verify a regular and consistent pattern of acquisition for grammatical morphemes in children's speech.

\section{Language of the Retanded}

Psycholinguistic studies of language development have focused on children of normal intelligence. Only recently has the psycholinguis- 
TABLE I

Brown's acquisition order for the 14 morphemes and the partial rank orders of acquisition of other investigators (1973)

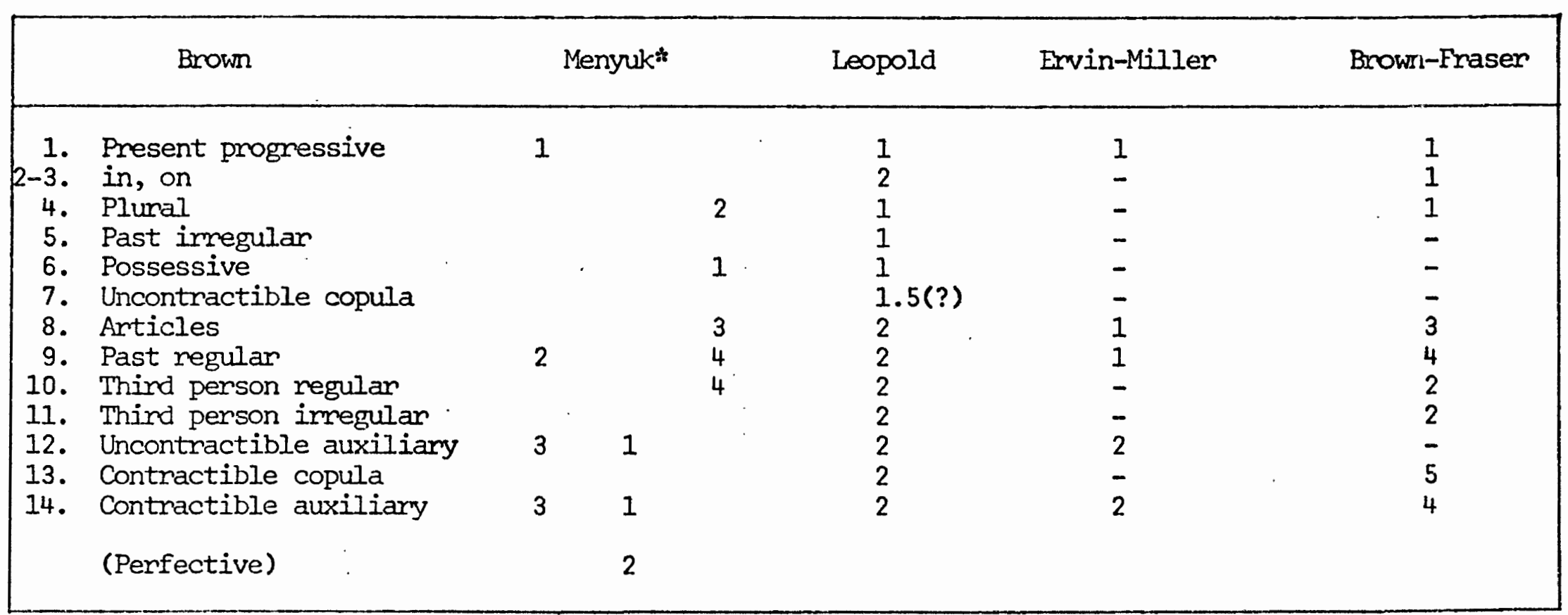

*There are three columns for Menyuk because in her rules she provides evidence relating three different small sets of morphemes with respect to one another in terms of acquisition onder but does not provide evidence relating morphemes from different sets. 
tic model been applied to mentally retanded populations. Jordan (1957) wrote, ". . Iinguistic studies of retanded persons have been slighted and our grasp of the facts is less than complete." Perhaps the basic consideration when investigating the linguistic capacity of the retanded is the nature of the relationship between subnormal intelligence and language. Intellectual functioning, on cognition, and langlage present a formidable issue to researchers in this area. Language development at lower levels of intelligence, specifically grammatical acquisition and performance, has received extensive attention in recent research. This section will discuss general features of language performance in retarded language.

\section{Variables to be Considered}

A recument question in the study of language development of retanded persons is the relationship of intelligence level, as defined by Intelligence Quotient (I.Q.), to language skilis. It is generally assumed that I.Q. is only one factor affecting speech and language development (Smith, 1971). Earlier research by Karlin and Strazzula (1952) suggested that a high comelation exists beitween I.Q. and language abilities. Goertzen (in Smith, 1971) also reported earliex that the incidence of language disonders varied according to intelljgence. More recent research does not support these earlier contentions. Rosenberg (1970) reported a Jow correlation between intelligence and the stage of language development in mongoloid children. He suggested that I.Q. may be relevant to linguistic skills which require learming, specifically, gramatical skills requiring trans- 
formational operations and semantics. Subnormal intelligence, then, may be responsible for specific limitations in linguistic competence and performance. Some of these limitations will be discussed later in this review.

A significant relationship between maturation and language development has been found, as discussed earlier (Lenneberg, et al., 1964). Menyuk (1971) stated that the language acquisition process in the mentally retarded "shows a slow and modest beginning until the early teens" and further suggested that the acquisition process is arrested in the early teens due to the completion of the maturation process. Rosenberg (1970) also concluded language development is more influenced by maturational factors than by intelligence.

Institutionalization, as a variable affecting language development has been mentioned by Yoder and Miller (1971). Limitations in vocabulary and sentence complexity observed by Lozar and Wepman (1972) in the speech of institutionalized educable retarded subjects were considered to be influenced by the environmental conditions. Although this variable was not discussed extensively, it may be of significance when comparing the language quality of retarded subjects to that of subjects with normal intelligence.

Incidence of Communication Disorders

The failure of most incidence studies to separate speech or articulation disorders from specific language disorders creates a confusing picture. Since most data represents the incidence of articulatory disorders, (Matthews, 1957) the figures below may be excessively high. One must also consider that institutionalization, maturation and intelligence vary from study to study. The following incidence data will be interpreted with the consideration that the figures only represent spe- 
cific populations.

An extremely high percentage of institutionalized mentaily retarded pensons have been reported to have speech defects. Spradlin (1963) reported 52 to 72 percent, Jondan (1967) reported an incidence of 66 percent of the population at Vineland Training School; and Yoder and Millen (1971) stated that 47 to 72 percent of institutionalized populations have speech defects.

Populations of retarded persons in special schools have shown a similar pattern of incidence. Yoder and Millen (1971) reported 72 to 92 percent of retarded children in day care schools have speech and language defects. Spradlin (1963) similarly reported an incidence of 72 to 82 percent of the severely retarded in day schools have speech disorders. By contrast, populations of mentally retanded children in the public schools were reported to show an incidence of 26 percent with communication problems (Yoder and Miller, 1971).

Severity of retandation has also been considered to be a factor influencing the incidence of speech and language probiems. Schlanger (1953) found an incidence of 60 percent in a population with an I.Q. range from 45 to 70 . Among the severely retanded, Kennedy (in Matthews, 1957) reported 71.87 percent of "institutionalized imbeciles" and 42.57 percent of "institutionalized morons" denonstrated speech defects.

Although a lack of consistency in incidence studies with regard to I.Q., age and environment exists, it is generally concluded that a higher incidence of communication disorders is found than in populations of normal intelligence (Keane, 1972). The incidence of spe- 
cific language deficits has not been established.

\section{Features of Retarded Language}

There is evidence in the literature that retarded persons are deficient in cormunication skills in general (Haas and Haas, 1972). The nature of language skills in the retarded has been described traditionally as a "developmental delay" when compared to the language skills of normals. Matthew's (1957) conclusion, that there is no evidence to suggest speech and language skills of mentally retanded children differ in kind from those of non-retarded children, underscores this theory. The slower biological development of retanded persons has been linked to a developmental delay in language acquisition (Jordan, 1967). The slowed acquisition process has generally been thought to be similar to normal development, but delayed. More recent studies of language performance in the retarded have questioned this earlien conclusion. Semmel, et al. (1968) described qualitative differences in the ability to provide abstract verbal definitions between retarded and non-retarded groups. This issue will be discussed further, later in this review.

Specific features of retarded language were described. by Karlin and Strazzula (1952). They reported a limited vocabulary, concrete use of language and a tendency to perseverate in words and ideas. Carison and Carlson (1945) stated that sentences are shorter, syntax was below age expentancy and there are emrors in noun and verb agreement in language patterns of retarded subjects. Jordan (1967), provided a similar description, saying the mentally retarded child acquired speech and language considerably later than the child with 
nomal intelligence. Keane (1972) has reported a lack of unique configuration of speech and language disorders among the retarded. Much of the above research has been in the area of phonology (Smith, 1971). Recent studies of the grammatical skills of the retarded have been interpreted to indicate both quantitative and qualitative differences in retarded language performance.

\section{Quantitative/Qualitative Theories}

A major issue in the study of language in the retarded has been the question of differences in development of various linguistic skills. Many researchers have found quantitative differences when comparing the retarded child's language performance to that of a nomal child (Lovell and Dixon, 1967). The data indicating a quantitative difference generally is interpreted as a developmental delay.

Other studies have brought researchers to the conclusion that a qualitative, or disordered, difference exists (Yoder and Miller 1971, and Sermel, et al. 1968). Sermel suggested mentally retarded subjects are less capable of performing abstract mental operations required to generalize grammatical patterns. Definitive answers to the quantitative/ qualitative issue remain to be stated. In light of the variables which influence larguage development and the high degree of individual variability in developmental rates, the issue becomes more complex (Lozar and Wepman, 1972). Yoder and Miller (1971) suggested that both a developnental delay and qualitative difference exist in the language of the retarded. The differences found in the language performance of the retanded will be discussed with panticular reference to the 
development of moxphological inflections.

Comparative Studies of Morphological Development

Lenneberg (1967) has stated that language "developmental milestones" are more influenced by maturational factors than by intelligence. He observed in the retarded, the entire developmental process is siowed during childhood and arrested during early teens. Based on this hypothesis, the grammatical development of the retarded should be similar to normal children, but delayed.

Lovell and Dixon (1967) used the research methods of Fraser, Bellugi and Brown (1963) to compare the imitation, comprehension and production skills of educable retanded to subjects of normal intelligence. They found that scores of 6 year old retanded subjects were nearly identical to those of normal 3 year old subjects. Sermel, et al. (1968) found that retarded subjects in public schools demonstrated word association responses similar to younger nomal children of a comparable mental age. Newfield and Schlanger (1968) administered Berko's nonsense itens and contrasting lexical items to educable retarded and normal children. Their results indicated retanded children learn moxphology in a marner comparable to normal children. Subjects in both groups tended to master regular and cormon allomorphs finst.

A different interpretation, which emphasizes a difference in kind, centers around the limited ability of the mentally retanded to generalize gramatical rules to abstract situations. Bemry (1972) reported a highly sigmificant difference in the comprehension skills of mildly 
retarded, severely retanded and normal subjects. The retarded subjects had greater difficulty comprehending a possessive sentence when it was contrasted with a present progressive sentence. Berry concluded the difference in grammatical compiexity could explain the differences in perfomance between retarded and nomal groups.

Lovell and Bradbury (1957). have investigated the development of English morphological inflections in a population of educationally subnormal special school children using Berko's method of inflecting novel stimuli. They found educationally subnormal (ESN) children between the ages of 14 and 15 did less well than Berko's normal finst gnaders. Further, they observed ESN children make relativaly little progress in inflecting lexicon and novel words during the school years. Both normal and ESN groups performed better using regular conmon aliomorphs than when using irregulam, less cormon forms. These authors concluded ESN subjects inflected lexicon words as much by usage and memory as by generation of rule forms.

Menyuk (1964) reported that children with delayed speech were unable to move beyond the use of elementary and general grammatical rules in their speech. Limitations in grammatical complexity were also observed by Semmel, et al. (1907) who hypothesized that educable mentally retarded children used more "sequential" strategies when encoding and decoding language, rather than more complex "paradignatic" strategies. A limited ability to abstract Iinguistic forms is reported elsewhere by Papania (1954), who investigated the verbal definitions of educable retanded and normal subjects.

The evidence of a qualitative difference mentioned above may not 
be opposed to the quantitative concept. A combined delay and limited grammatical capacity may exist concurmently in the language skills of the mentally retarded. The importance of this issue may not be in answering the quantitative/qualitative question, but in describing how retarded subjects learn language. Yoder and Millen (1971) suggested evaluation of retarded subjects' perfomance at all levels of language is important to discover linguistic strengths on effective language behavion, rather than defective behavior.

\section{Assessment of Language Skills}

Assessment of language skills has become increasingly influenced by psycholinguistic models of language competence. The problem of inferming competence through the analysis of imperfect performance data has been emphasized throughout the iiterature (Ferguson and Slobin, 1973). The need for complete evaluation at ali levels is stressed by. Carrow (1971) and Rosenberg (1970). This section will review the psycholinguistic model for language assessment and its application, specifically at the level of morphological development.

\section{Competence and Performance}

The concept of Iinguistic competence is basic to the theory of generative grammar. As disclissed earlier in this review, Chomsky (1971) postulated the adult speaker has knowledge or competence with which to juage the gramnaticalness of sentences. The task of the psycholinguist is to discover the child's stage of Iinguistic competence, or the level of his gramatical development. This is done through 
empirical observation and evaluation of perfomance at specific levels of language. Ruder (1972) described the penformance data as the "language corpus" from which the linguist attermts to infer and describe the child's knowledge of language, or competence.

\section{Models of Assessment}

In order to best describe the child's stage of linguistic competence, analysis of perfomance at several levels is necessary. Rosenbeng (1970) has presented a model of assessment which specifies that analysis of performance should be on three levels: imitation, comprehension and production. Carrow (1971) characterized these levels somewhat differently in her model of assessment as three levels of language functions which are represented in performance. She defined Level I as sensation, Level II as perception and Level III as language formulation. Level III is the most complex, serving to integrate the conceptual and Iinguistic systems. Carrow (1971) emphasized the need to evaluate each individual subject at all levels of language functioning, altering test items to suit the need for complete diagnosis. Seigal (1972) also suggested an individualistic approach to Iinguistic evaluation yields more valuable information.

Yoder and Miller (1971) outlined some basic considerations for a language evaluation strategy.

1. What is the child's comprehension of language?

2. What is the level of production of language?

3. What is the gap between the child's comprehension and production of language?

4. Wrat is the gap between language abilities (comprehension and production) of the child and that of the language users in the community?

The suggested considerations for assessment by Carrow (1971) and 
Yoder and Miller (1.971) have particular relevance for language evaluation of the mentally retarded. Two of the specific tools designed to determine linguistic competence through eliciting the performance of morphological rules will be discussed in the following sections.

\section{Imitation, Comprehersion and Froduction Test}

Fraser, Bellugi and Brown (1963) have investigated the hypothesis that comprehension precedes production of language. They designed a test, The Imitation, Comprehension and Production Test, which examined linguistic performance at these three levels. Ten gramatical contrasts were presented to their subjects, 12 normal children between the ages of 37 and 43 months. Thein general findings indicated that production (P), was less advanced than comprehension, but that initation (I) was more advanced than comprehension (C). These earlier findings recently have been questioned and re-interpreted by Ferguson and Slobin (1973). These authors have stated that the superiority of imitation over comprehension reported by Fraser, Bellugi and Brown may have been a result of the complex items presented in the ICP test itself. Ferguson and Slobin have also suggested that imitation may actually appear to be superior to comprehension and production when forms are presented at the child's "edge" of competence. He may recognize and imitate these forms correctly but may not have mastered them well enough for use in comprehension and production.

The ten grammatical contrasts selected for the ICP were based upon previous work of Brown and Fraser (1963) that showed complete mastery over these forms was not common in children under 4 years of age. 
The ten problems were presented in similar order in initation, comprehension and production tasks. The ten contrasts are:

1. Mass Noun/Count noun

2. Singular/Plural, marked by inflections

3. Singular/Plural, marked by is and are

4. Present progressive/ Past tense

5. Present progressive/ Future tense

6. Affirmative Negative

7. Singular/Plural, of third person possessive

8. Subject/Object, in the active voice

9. Subject/Object, in the passive voice

10. Indirect object/Direct object

For each grammatical contrast, six examples were constructed. Two utterance pains were assigned to each of the tasks, I, C and P. Each stirnulus was accompanied by a brightly colored line drawing.

The ICP Test is not standardized, but has been said to yield data comparable with the Michigan Pictume Language Inventory by Lerea (Camow, 1971). Lovell and Dixon (1967) have used the ICP procedure with 6 year old educable mentally retarded children. They reported the retarded subjects performed comparably to normal 3 year old subjects. Further research with older retarded and normal subjects is needed to describe the grammatical skills of that age group.

\section{Berko's Test}

Jean Berko (1958) made an important methodological contribution to the investigation of language development with her study of English morphological developnent in normal children. Her test of morphology was designed to elicit children's productive control of various inflections by presenting novel or nonsense syllables in contexts requiring inflections. The specific inflections tested were plural, possessives, thind person singular, past tense, present progressive 
and the superlative. In onder to test for the knowledge of morphological rules of different types and under varying conditions, a list of nonsense words which followed the phonological rules of English was constructed. These 27 items were presented with cartcon figures to subjects between the ages of 4 and 7 years.

Berko's results showed that children made significantly more errors with the less common allomorphs of the plunal than with possessives. Most of her subjects comrectly formed the less common allomorph $/ \theta Z /$ with a lexical word, but had difficulty generalizing it to nonsense words.

Berko's approach has been used widely in the study of morphological development of normal and mentally retarded children. Anisfeld and Tucker (1973) have most recently refined Berko's technique by matching the nonsense worts phonetically, with the exception of one phoneme. Their extensive study of pluralization with minimal nonsense pairs has shown the complexity of pluralization. Berko's test has also been used with educable mentally retarded children (Lovell and Bradbury, 1967), (Newfield and Schlanger, 1968), (Dever, 1972), (Wiig, et al., 1972). Newfield and Schlanger (1968) concluded that retarded children penfom similarly to younger nomal subjects. Dever (1972), questioned the applicability of Berko's test to predicting the productive control of morphology in retarded subjects. He discussed the need fon other measures of morphology in addition to nonsense stimuli.

\section{Surimary}

This review has briefly sumarized the broad applications of psy- 
cholinguistic theory with regard to language development in the retanded. A normal model of language development was presented in which the stages of increasing language competence have been observed to be fairly consistent, although children vary in age of acquisition. The productive body of psycholinguistic research provides an important framework for studying linguistic skills of the retarded.

Representative profiles of langlage competence are not yet available for retanded populations. Considering the complexity of language development and the varied limitations in retanded persons, this may not be a realistic objective. Perhaps only developmental trends can be established, with the main emphasis on individual language capacity. Further description of performance variants in retanded persons is needed to define positively particular cormunication strengths.

Brow and Fraser (1964) have stated:

Normal adults speaking their native language seem to possess a set of rules of word construction and sentence construction which enable them to go beyond speech they have actually heard and practiced to the creation of lawful novelties.

In the terms of transformational grammar, linguistic competence is indicated by consistencies of Iinguistic behavion or performance. Of particulan importance to this study are patterns of performance in the speech of EMR adolescents when using certain morphological rules called inflections. 
CHAPTER III

METHODS AND PROCEDURES

\section{Subjects}

This study included twenty-four subjects from two populations, educable mentally retarded (EMR) adolescents and school-aged children of nomal intelligence. In the experimental group, the EMR subjects ranged in age from 15 years, 6 months to 20 years, 1 month with a mean age of 17 years, 0 months. Each experimental subject was matched for mentai age to a control subject of normal intelligence. The ages of the control group ranged from 8 years, 1 monts to 15 years, 1 month with a mean age of 11 years, 4 months.

Twelve experimental subjects were randomly selected from a subject pool of thirty-one students placed in a vocational prognam for the educably retarded in the Vancouver School District. Twelve control subjects were selected from school aged children of normal intelligence placed in regular classrooms of similar mental ages to experimentais.

A]l subjects were screened for hearing acuity, articulation and overall speech intelligibility. Variables of sex, socicecononic status and cultural background were not controlled. Additionally, experimental subjects were screened for previcus language training and diagnosis of educable retardation.

Previous Language Training 
Subjects who had previously received formal language intervention with the Monterey Language Program or the Distan Language Program were excluded from this study.

Mental Age

Mental age was estimated by adninistering the Peabody Picture Vocabulary Test (FPVT), Form B (Dunn, 1965) to all subjects and deriving a raw score. Experimental subjects were selected first and then each matched to a control subject within three points of naw score on the PPVT. PPVT raw scores ranged from 106 to 68 in the experimental group with a mean score of 83.6. PPVT raw scores ranged from 106 to 67 in the control group with a mean of 83.4 (Table II and III).

\section{Diagnosis}

School records and teachers were consulted in onder to verify the diagnosis of educable retardation for the experimental group.

\section{Hearing Acuity}

Each subject passed a hearing acuity screening test presented bilaterally at $25 \mathrm{~dB}$ in the speech frequencies, $500 \mathrm{~Hz}, 1 \mathrm{~K} \mathrm{~Hz}, 2 \mathrm{~K} \mathrm{~Hz}$ and 4K $\mathrm{Hz}$. All subjects were screened using a Beltone audioneter Model 10-C). Hearing testing was performed in a quiet office with the door closed.

Articulation and Speech Intelligibility

A brief sample of a speech and articulation performance was ob- 
TABLE II

CHRONOLOGICAI, AGES AND RAW SCORES ON PFVT, FORM B FOR EXPERIMENTAL AND CONIROL GROUP

\begin{tabular}{|c|c|c|c|c|c|}
\hline \multirow[b]{2}{*}{ Subject } & \multicolumn{2}{|c|}{ Experimental Group } & \multicolumn{3}{|c|}{ Control Group } \\
\hline & C.A. & PPVT R.S. & Subject & C.A. & PPVT R.S. \\
\hline $\begin{array}{r}1 \\
2 \\
3 \\
4 \\
5 \\
6 \\
7 \\
8 \\
9 \\
10 \\
11 \\
12\end{array}$ & $\begin{array}{l}16-1 \\
16-8 \\
16-0 \\
17-5 \\
17-10 \\
16-10 \\
15-6 \\
18-4 \\
15-10 \\
16-6 \\
20-1 \\
16-9\end{array}$ & $\begin{array}{r}106 \\
98 \\
93 \\
91 \\
90 \\
82 \\
82 \\
81 \\
80 \\
79 \\
74 \\
68\end{array}$ & $\begin{array}{l}13 \\
14 \\
15 \\
16 \\
17 \\
18 \\
19 \\
20 \\
21 \\
22 \\
23 \\
24\end{array}$ & $\begin{array}{c}14-0 \\
12-5 \\
12-5 \\
12-7 \\
15-4 \\
9-9 \\
11-11 \\
13-1 \\
10-2 \\
10-7 \\
7-9 \\
8-1\end{array}$ & $\begin{array}{r}106 \\
100 \\
93 \\
93 \\
88 \\
82 \\
81 \\
80 \\
79 \\
76 \\
72 \\
67\end{array}$ \\
\hline
\end{tabular}

TABLE III

MEAN CHRONOLOGICAL AGES AND MEAN RAW SCORES ON PPVT FOR BOTH GROUPS

\begin{tabular}{|c|c|c|c|}
\hline \multicolumn{2}{|c|}{ Experinental Group } & \multicolumn{2}{c|}{ Control Group } \\
\hline Mean C.A. & Mean R.S. & Mean C.A. & Mean R.S. \\
\hline $17-0$ & 83.6 & $11-3$ & 83.4 \\
\hline
\end{tabular}


tained from each subject. In order to evoke spontaneous speech, questions were asked by this investigator concerning hobbies, family iffe and pets. The subjects' responses were tape recorded and judged according to general intelligibility. Subjects with 100 percent speech intelligibility were included in this study. Additionally, each subject was required to count to ten and to repeat several sentences after the investigator as a measure of articulation for the phonemes; $/ \mathrm{s} /, / \mathrm{z} /, / \mathrm{t} /, / \mathrm{d} /$ and $/ \mathrm{g} /$, which are necessary consonants for English inflections. Subjects with severely distorted articulation for these particular phonemes were excluded from the study.

\section{Instrumentation}

This investigator administered a modified form of Berko's Test of English Morphology (BTEM) (Berko, 1958) and a modified form of the Imitation, Comprehension and Production Test (ICP) (Fraser, Bellugi and Brown, 1963) to each subject. Twelve itens were selected from the BIEI which test four inflectional morpehmes; plural, past tense, possessives and present progressive. Additionally, stimulus items were shortened to eliminate excessive verbal information to the subject. Twelve prourction items, four comprehension items and four imitation items were selected from the ICP test which were grammatical contrasts for the same inflecticnal morphemes listed above. A furthen modification of the ICP was the construction of new iteris changing possessive promouns to nouns in sirgular and plural contrasts (See Appendix A). 
Test Administration

Testing was conducted individually in a quiet room with the investigator and the subject seated side by side at a table. Each test was administered as follows:

1. BTEM was administered using verbal and visual stimuli. The investigator presented a colored cartoon drawing of an imaginary creature and named the figure. The subject was then asked to name the picture as originally named by the investigator. The subject was then required to respond verbally when asked a question which indicated the necessary inflection. Specific stimuli are shown in Appendix A.

2. The ICP test was administered according to the instructions provided by Fraser, Bellugi and Brown (1963) and Brown (1975). Colored line drawings representing familiar vocabulary accompanied production and comprehension items. Imitation items were given verbalily without pictures. The instructions for the ICP are provided in Appendix A.

\section{Data Analysis}

Comparisons in grammatical performance were made within and between the experimental and control groups. Mean scores and standand deviations were determined for the performance of each group on the production items of the ICP and BTEM. Levels of performance on the ICP: initation, comprehension and production, were also compared for the experimental group.

Tests were performed to compare the following:

1. A comparison was made between the performance of the experimental group on the ICP and BTEM. 
2. A comparison was madie between the performance of the control group on the ICP and BTEM.

3. Comparisons were made between the mean scores of experimentals and controls on the ICP.

4. Comparisons were made between the mean scores of the experimentals and the controls on BTEM.

Rank order correlations were determined between levels of performance on the ICP for the experimental group. Comparisons were rnade between $I$ and $C, I$ and $P$ and $C$ and $P$.

Chi-square analysis was used to compare the number of experimental and control subjects using inflections in four categories correctly. Chi-square analysis was performed in three conditions: (1) between combined categories of inflection on the ICP and BTEM; (2) by separate categories of inflection on the ICP and BTEM and (3) by item analysis on the ICP and BIFM. 
CHAPTER IV

RESULTS AND DISCUSSION

\section{RESULTS}

The purpose of this study was to investigate the kinds of differences exhibited in the granmatical performance of educable meritally retanded (EMR) adolescents using four grammatical morphemes: inflections for plucal, possessive, present progressive and past tense. This study was designed to compare the grammatical performance of two groups, EMR adolescents and subjects of normal intelligence matchèd by mental age. Comparisons of granmatical performance using these four inflections were made using lexical and novel (nonsense) stimuli. Modifications of two evaluations were used to assess the use of inflections: (1) The Imitation, Comprehension and Production Test (ICP) (Fraser, Bellugi and Brown, 1963) provided lexical stimuli and (2) Berko's Test of English Morphoiogy (BTEM) (Berko, 1958) provided novel stimuli. Comparisons in performance were made between the production items of the ICP and BTEM within and between groups. Additionally, patterns of performance in the experimental group (EMR subjects) were examined. It should be noted that all comparisons in performance on the ICP refer to production itens only, unless otherwise stated.

\section{Comparisons in Performance Within Groups}

The performance of the experimental subjects on the ICP was compared 
with thein performance on the BMEM. The same comparison was made in the control group. Within the experimental group, comelations were determined amng levels of performance on the ICP.

Penformance of Experimental Subjects. A t test was performed to compare the mear percent scores of the experimental subjects (EMR group) on the ICP and BIFA. The mean score for the ICP was 73 percent with a standard deviation of 13 percerit; whereas, the mean score for the BIEM was 61 percent with a standard deviation of 23 percent. The resulting $t$ value of 1.03 was not considered statistically significant, as it is below the 0.05 level. Tabie IV illustrates the means, standand deviations and $t$ value for the performance of EMR subjects for the ICP and BTEM.

Performarice of the control Group. For the control group, the mean score on the ICP was 90 percent with a standand deviation of 8 percent. The mean score for the BIEM was also 90 percent and the standard deviation, 8 percent. The identical mean scores and standard deviations resulted in a $t$ value of 0 since no difference existed between the two tests (Table IV).

TABLE IV

COMPARISON OF INIERTEST PERFORMANCE OF EMR AND CONIROL GROUPS $(N=12)$

\begin{tabular}{|l|c|c|c|}
\hline & Mean Score in percent & $\begin{array}{c}\text { Standard Deviation } \\
\text { in percent }\end{array}$ & $t$ \\
\hline $\begin{array}{l}\text { ICP } \\
\text { (Experimentals) }\end{array}$ & 73 & 13 & $1.03 *$ \\
BTEM & 61 & 23 & 8 \\
\hline $\begin{array}{l}\text { (Controls) } \\
\text { ICP }\end{array}$ & 90 & 8 & $0 \%$ \\
\hline BTEM & 90 & $80.01 \mathrm{p}=2.20$ \\
\hline
\end{tabular}


Levels of Performance in the Experimental Group. The levels of performance on the ICP test (imitation, comprehension and production) items were correlated within the EMR group. Rank order comelations among levels of imitation, comprehension and production revealed high positive correlations above the 0.01 level of significance. Table $V$ displays rank onder comelations for initation versus comprehension, imitation versus production and comprehension versus production.

TABLE V

INTER-CORREIATION OF ICP TEST COMPONENTS FOR EXPERIMENTAL GROUP ( $N=12)$

\begin{tabular}{|c|c|}
\hline & $\begin{array}{l}\text { Correlation } \\
\text { Coefficient }\end{array}$ \\
\hline $\begin{array}{l}\text { Imitation } \\
\quad \text { versus } \\
\text { Comprehension }\end{array}$ & $0.872 *$ \\
\hline $\begin{array}{l}\text { Comprehension } \\
\text { versus } \\
\text { Production }\end{array}$ & $0.871^{*}$ \\
\hline $\begin{array}{l}\text { Imitation } \\
\text { versus } \\
\text { Production }\end{array}$ & $0.924 *$ \\
\hline
\end{tabular}

Comparisons in Performance Between Groups

The performance of the EMR subjects on the ICP and BTEM was compared to that of the matched normal subjects using $t$ test and chi-square 
analysis. A t test comparison between the mean scores of the EMR and the control groups on the ICP revealed no statistically significant difference. The resulting $t$ value of 1.88 was considerably below the 0.05 level of significance. Using a $t$ test, the mean score on the BTEM of the control group was compared to that of the experimental group. A $t$ value of 2.07 resulted, which is statistically significant at the 0.05 level (Table VI).

\section{TABLE VI}

COMPARISON OF MEAN SCORES OF. EMR AND CONTROLS ON ICP AND BTEM $(N=24)$

\begin{tabular}{|l|c|c|c|}
\hline Test Group & Mean Score in percent & $\begin{array}{c}\text { Standard Deviation } \\
\text { in percent }\end{array}$ & $t$ \\
\hline $\begin{array}{c}\text { ICP } \\
(\text { Experimental) } \\
\begin{array}{c}\text { ICP } \\
\text { (Controls) }\end{array}\end{array}$ & 73 & 13 & 1.88 \\
\hline $\begin{array}{c}\text { BIEM } \\
\text { (Experimentals } \\
\text { BTEM }\end{array}$ & 80 & 8 & 23 \\
(Controls)
\end{tabular}

$* 0.05 p=2.07$

Using chi-square analysis, comparisons were also made between the numbers of experimental and control subjects using correct inflections for each item of the ICP and BTEM.

Chi-square analysis was performed to compare the experimental and 
control groups by combining corresponding categories of inflection on the two tests, ICP and BTEM. A chi-square value of 8.60 for past tense on both tests was significant above the 0.01 level. Chi-square values comparing the performance of the experimental and control groups by combined categories of inflection on the ICP and BTEM are illustrated in Table VII.

\section{TABLE VII}

CHI SQUARE VALUES COMPARING PERFORMANCE OF EMR AND CONTROL GROUPS BY COMBINED INFLECTION CATEGORIES ON ICP AND BTEM

$(\mathrm{N}=24)$

\begin{tabular}{|c|c|c|c|}
\hline & & & \\
\hline $\begin{array}{c}\text { Plural } \\
x^{2}\end{array}$ & $\begin{array}{c}\text { Possessive } \\
x^{2}\end{array}$ & $\begin{array}{c}\text { Past tense } \\
x^{2}\end{array}$ & $\begin{array}{c}\text { Present Progressive } \\
x^{2}\end{array}$ \\
\hline 3.05 & 1.609 & $8.60^{*}$ & 1.878 \\
\hline
\end{tabular}

Chi-square analysis was used to compare the performance of EMR subjects to normal control subjects in the use of four inflections, compared by categories on the two tests. No statistically significant differences were found when comparing the performance of EMR and normal controls in categories of inflections on the ICP. A statistically significant difference was found between the performance of EMR and normal subjects, using the inflection for the past tense on BTEM. A chi-square value of 13.99 was considerably above the 0.01 level of significance. Chi-square values comparing the performance of both 
groups by categories of inflection on the ICP and BTEM are shown in Table VIII.

TABLE VIII

CHI SQUARE VALUES COMPARING EMR AND CONTROL GROUPS BY PERFORMANCE IN FOUR INFLECTION CATEGORIES ON ICP AND BTEM SEPARATELY $(\mathrm{N}=24)$

\begin{tabular}{|c|c|c|c|c|}
\hline & $\begin{array}{c}\text { PIural } \\
\mathrm{x}^{2}\end{array}$ & $\begin{array}{c}\text { Possessive } \\
\mathrm{x}^{2}\end{array}$ & $\begin{array}{c}\text { Past tense } \\
\mathrm{x}^{2}\end{array}$ & $\begin{array}{c}\text { Present } \\
\text { Progressive } \\
\mathrm{x}^{2}\end{array}$ \\
\hline ICP & 1.2 & 1.36 & 1.89 & .0448 \\
\hline BTEM & 3.108 & 2.847 & $13.89 \%$ & 2.18 \\
\hline
\end{tabular}

${ }^{*} x^{2} \operatorname{sig} \cdot 0.01$ 10f $=6.64$

The comparisons of the response patterns of the two groups for each item showed no statistically significant differences in performance on the ICP. Performance on isolated items using inflections for plurals and possessives approached the 0.05 level of significance with respective chi-square values of 3.33 and 2.66 . Chi-square values for ICP item comparisons are listed in Table IX.

TABLE IX

CHI SQUARE VALUES FOR ITEM COMPARISON BETWEEN GROUPS ON THE ICP $(\mathrm{N}=24)$

\begin{tabular}{|c|c|c|c|c|c|c|c|}
\hline & & & & & & & \\
\hline Item & $\begin{array}{c}\text { Plural } \\
x^{2} \\
\end{array}$ & Item & $\begin{array}{c}\text { Possessive } \\
x^{2} \\
\end{array}$ & Item & $\begin{array}{l}\text { Past } \\
\text { tense } \\
x^{2} \\
\end{array}$ & Item & $\begin{array}{l}\text { Present } \\
\text { Progressive } \\
x^{2}\end{array}$ \\
\hline $\begin{array}{l}1 a \\
2 b \\
4 a \\
6 a \\
8 a\end{array}$ & $\begin{array}{l}0.25 \\
0.375 \\
0.375 \\
0.562 \\
0.12\end{array}$ & $\begin{array}{r}2 a \\
6 a \\
9 b \\
12 a\end{array}$ & $\begin{array}{l}0.562 \\
.00694 \\
1.04 \\
.00694\end{array}$ & $\begin{array}{r}3 \mathrm{~b} \\
5 \mathrm{a} \\
7 \mathrm{~b} \\
10 \mathrm{~b}\end{array}$ & $\begin{array}{l}2.66 \\
0.38 \\
3.33 \\
1.74\end{array}$ & $\begin{array}{r}3 a \\
5 b \\
7 a \\
10 a\end{array}$ & $\begin{array}{l}0.25 \\
0.562 \\
0.375 \\
0.375\end{array}$ \\
\hline
\end{tabular}


Chi-square analysis of itens on the BTEM showed statistically significant differences in performance between groups on some items requiring the use of inflections for plural, possessive and past tense. Highly significant differences above the 0.01 level were. found in the use of the plural and possessive allomorph, /az/, and past tense, /ad /, with respective chi-square values of $8.42,13.6$ and 13.99 . Differences in the use of the past tense allomorph, /d/, exceeded the 0.05 level of significance with a chi-square value of 4.195 . The use of the allomorph for inflecting plural, /z/ with a chi-square value of 3.33 , approached the 0.05 level of significance. In all of the reported differences, EMR subjects performed significantly poorer than the control group (See Table X).

TABLE X

CHI SQUARE VALUES FOR ITEM COMPARISONS BY GROUPS ON THE BTEM (N-24)

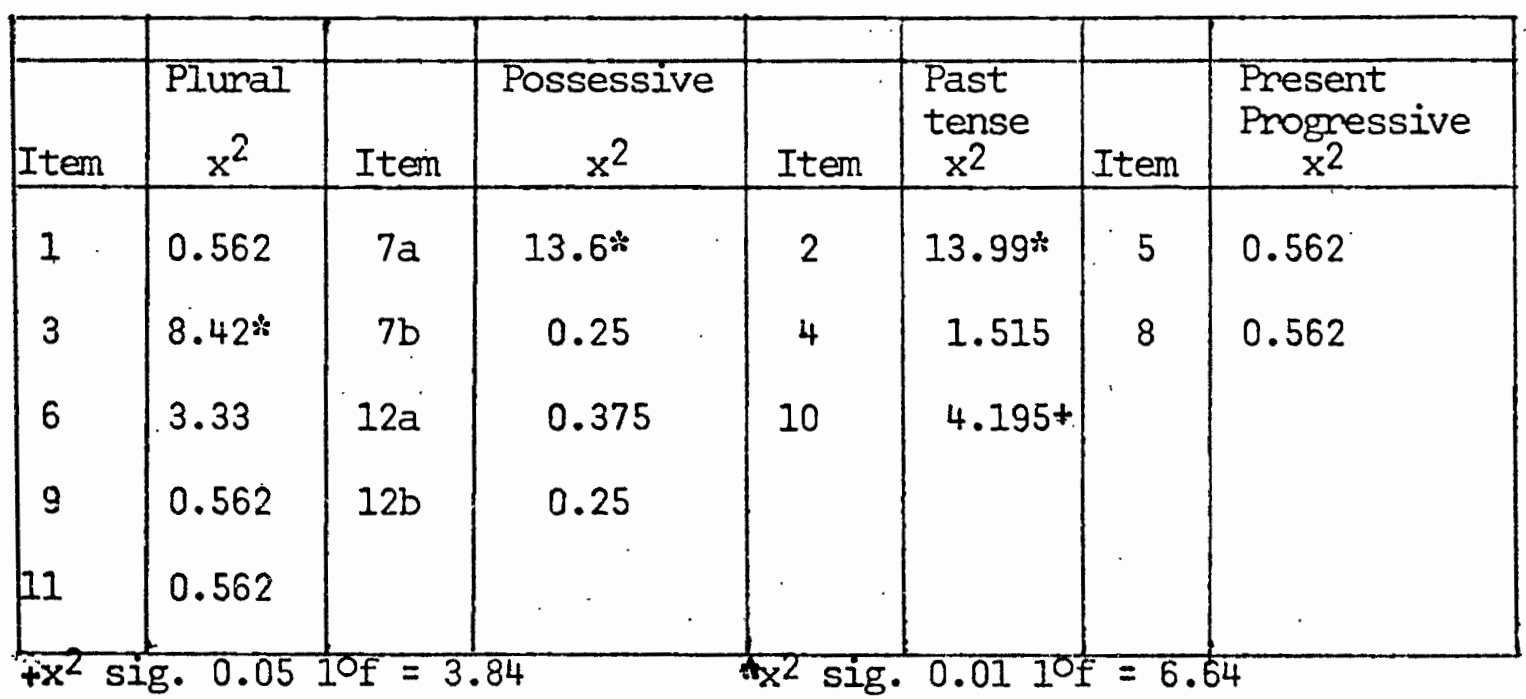

Inter-Group versus Intra-Group Comparisons

The significance of intra-group comparisons relative to performance 
on the ICP and BTEM was not analyzed statistically because of the limited amount of data provided by the small number of subjects in this study. Inspection of the data suggested a high degree of similarity of performance within the control group and a lesser degree of similarity within the experimental group. These trends were observed in the mean scores and standard deviations for each test within groups. A mean score of 90 percent with a standard deviation of 8 percent for both the ICP and the BTEM in the control group suggested a small degree of variance of performance for that group. A greater variance was shown in the performance of the experimental group with a mean score of 73 percent and standard deviation of 13 percent on the ICP and a mean score of 61 percent and standard deviation of 23 percent on BTEM. The reader may refer to Appendix B for more detailed observation which lists individual scores by percent for each group on the ICP and BTEIY.

The numbers of experimental and control subjects using correct inflections on the ICP and BTEM are illustrated in Figures 2, 3, 4 and 5 by categories of inflection (plural, possessive, present progressive and past tense). These figures emphasize certain patterns of performance which are common to each respective group. For example, most experimental subjects, 10 of 12 , failed to use the allomorph, $/ \partial z /$, to inlect plural and possessive nouns. The use of the past tense allomorphs, /d/, /t/, and /ad/ also appeared difficult for the experimental groups since slightly less than half of the subjects used these allomorphs correctly. Chi-square analysis reported in the previous section substantiated these observed trends of commonality within the 
No.s

of Subjects

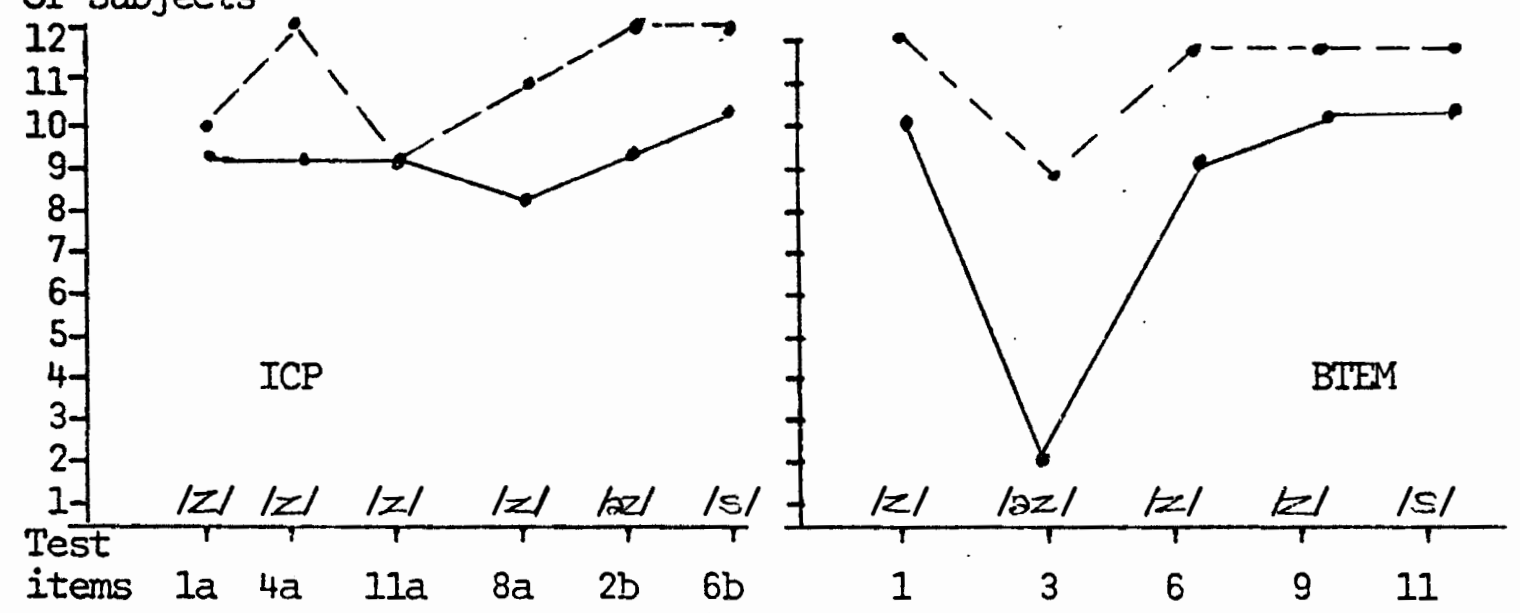

Figure 2. Numbers of Control and Experimental subjects using inflections for plunal correctly on ICP and BTEM.

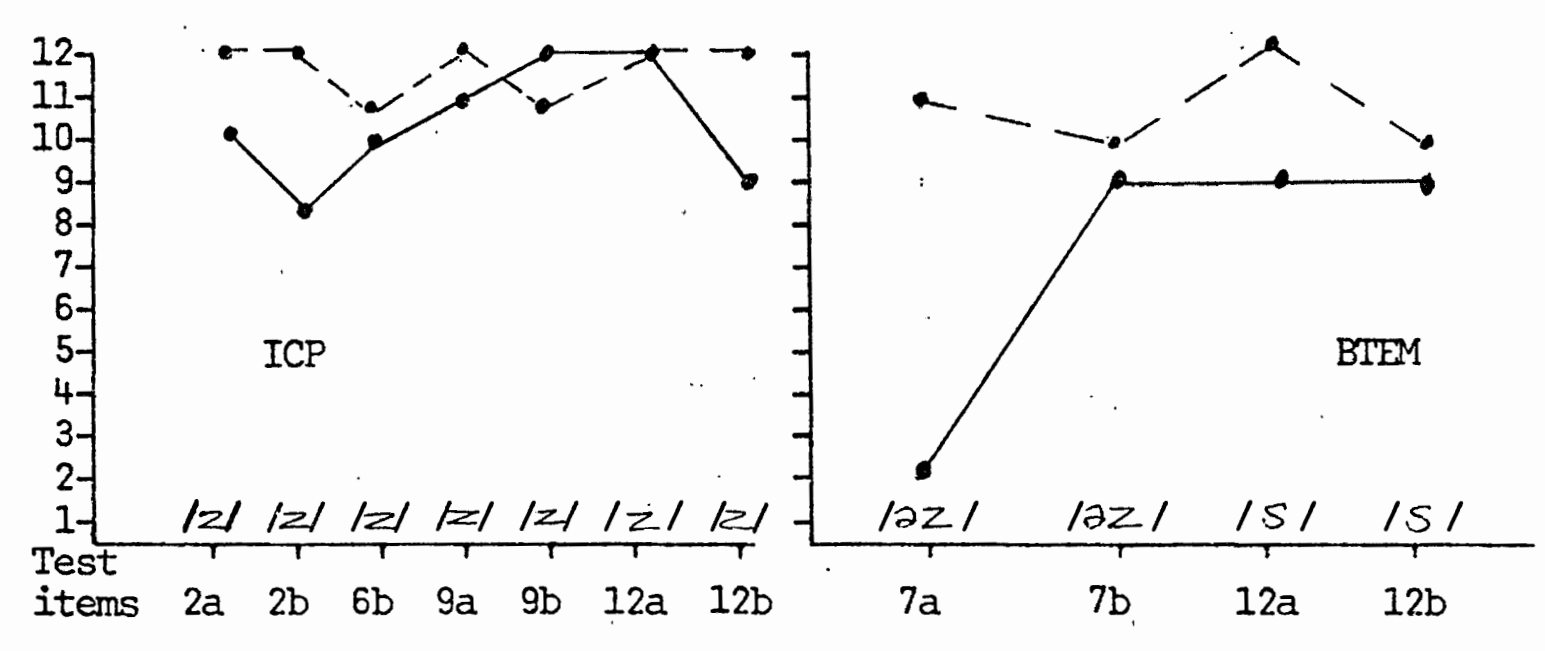

Figure 3. Numbers of experimental and control subjects using possessive inflections correctly on ICP and BTEY. 
No.s of

Subjects
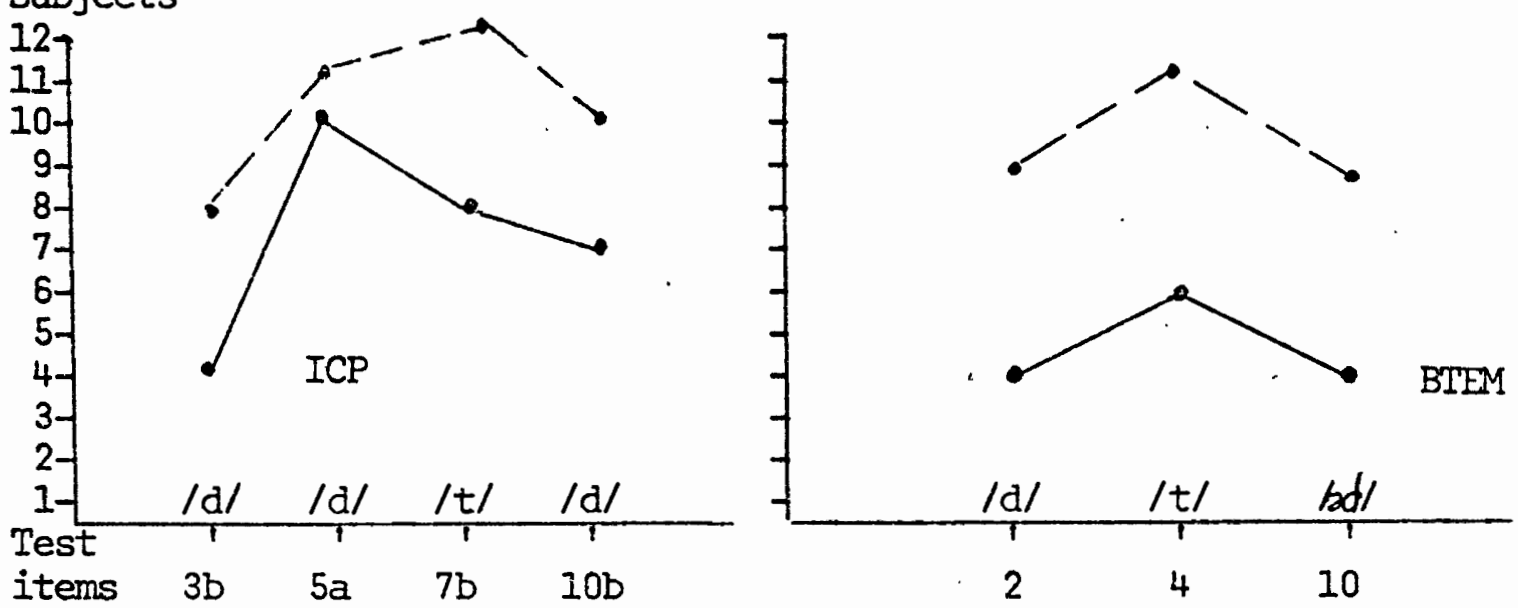

Figure 4. Numbers of experimental and control subjects using inflection for past tense correctly on ICP and BTEM.
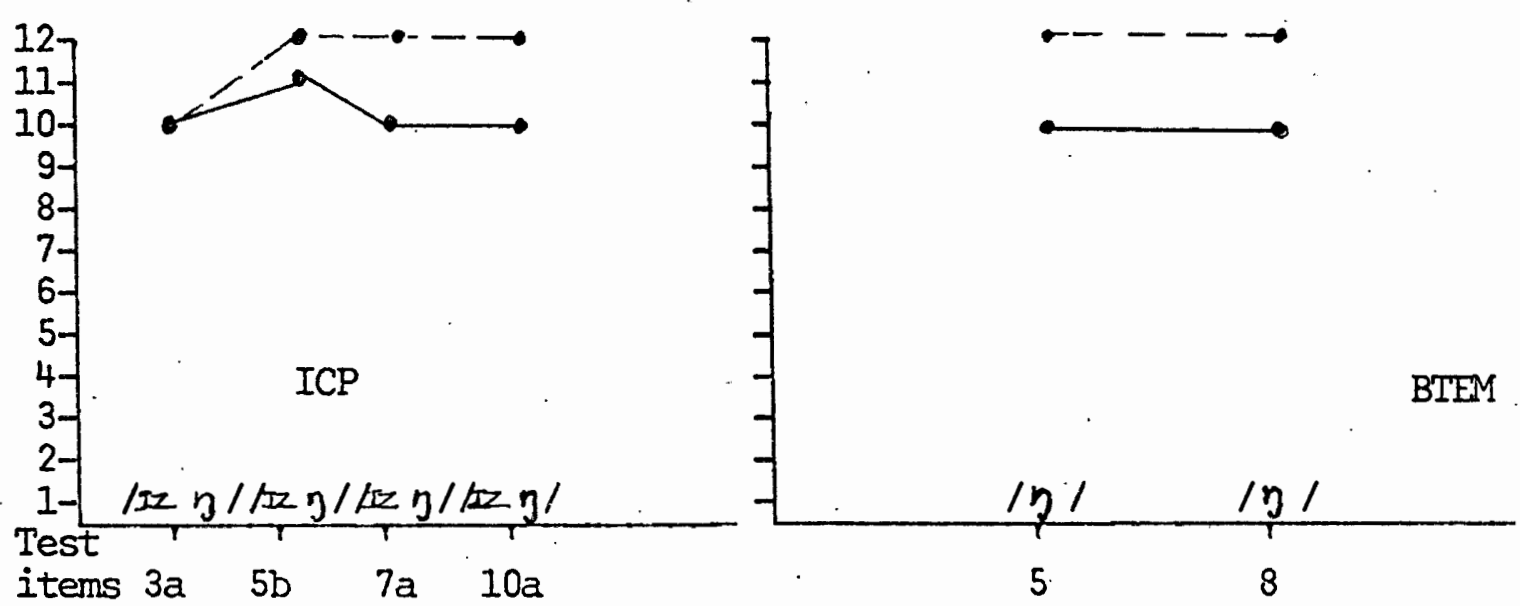

Figure 5. Numbers of experimentals and controls using present progressive inflection correctly on ICP and BTEM. 
control and experimental groups.

Although not analyzed statistically, there appeared to be a higher degree of inter-group variation than variation within groups in the use of gramatical morphemes to inflect plural, possessive, present progressive and past tense.

\section{Discussion}

This investigation sought to answer three essential questions relative to the differences in the use of English inflection for plural, possessive, past tense and present progressive by educable mentally retarded (EMR) adolescents when compared to normal controls matched by mental age to each experimental subject. Statistical findings will be interpreted in this section relative to each essential question investigated.

The first question was: In which tasks do EMR adolescents perform more successfujly? There were two parts to this question. The finst compared performance using lexical and non-lexical stimuli. . A comparison between the mean scores of the production items on the ICP and BTEM within the experimental group revealed a difference of 12 percent. Although not statistically significant, this difference indicated that EMR adolescents used inflections for lexical stimuli slightly more successfully than for novel stimuli. When considering research reported by Semmel et al. (1968), the EMR subjects in this study performed better than expected using novel wonds. Sermel et al. (1968) suggested limitations in the ability of the mentally retanded to abstract granmatical rules. 
The statistically nonsignificant differences found between the mean scores of the control group on the ICP and BTEM indicated these two tests are highly similar instmuments. Generally, these differences between the mean scores within groups on the production items of the ICP and BTEY suggested the two tests measured the same variables of linguistic performance, specifically the use of certain gramatical morphemes called inflections. These findings do not support research by Dever (1972) who suggested the BTEM provided a poor prediction of productive morphology in the speech of EMR children. In this study, the BIEM and the ICP provided highly similar data in the control group. Similarities in the performance of the experimental group on the two instmments also indicated BIEM to be a valid assessment of productive control of inflections in the speech of EMR adolescents. Figure 6 illustrates the similarities between mean percent scores within groups on the ICP and BIEM.

Supplementary to the first question, this investigation sought to detemine at what level EMR adolescents performed more successfully on the ICP test: imitation (I), comprehension (C) or production (P). Rank order correlations revealed high positive comrelations between I, $C$ and $F$, indicating equal performance at all levels for EMR subjects. These findings do not support earlier research by Fraser and Bellugi and Brown (1963). In their study of gramatical contrasts with normal children from the ages of 37 to 43 months, these authors concluded $P$ was less advanced than $C$, but I was more advanced than $C$. The present investigation did not provide evidence to support differences in performance levels reported by Fraser, Bellugi and Brown (1963). 


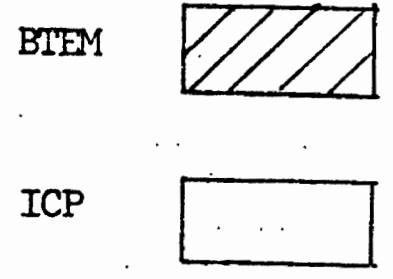

\section{Mean}

Percent Score

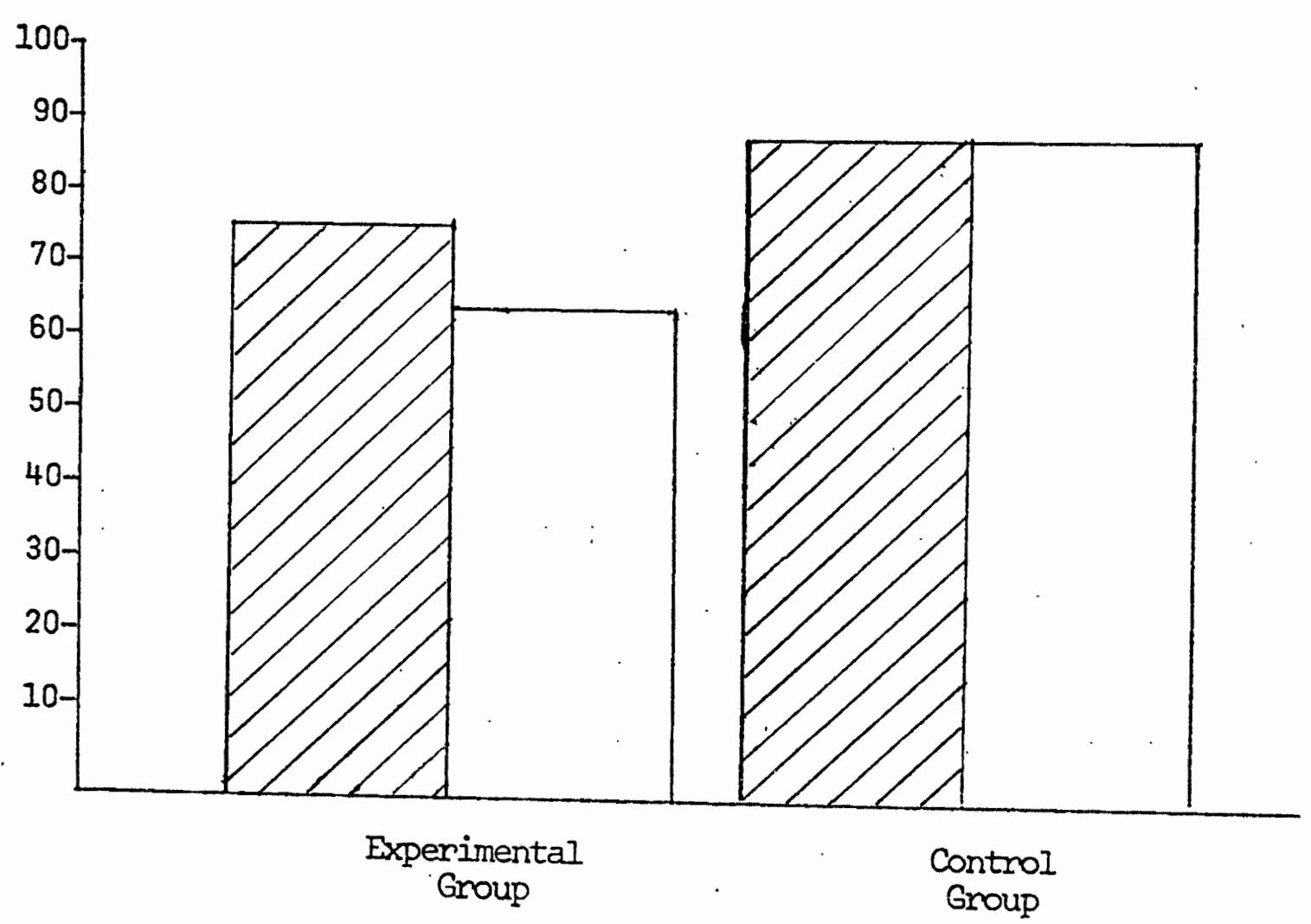

Figure 6. Mean percent scores compared within groups on the 
The second question was: Do educable mentally retarded adolescents demonstrate significant differences in their performance when compared to normal subjects with the same mental age scores? There were three components to this question; the first was a comparison between the performance of the experimental and control group's ICP and BTEM scores. No statistically significant differences were found between the mean scores of the experimental group and control group for the production items of ICP. A difference between the mean scores of 17 percent indicated the EMR adolescents penformed only slightly poorer than normal control subjects when required to produce verbally four English inflections for lexical stimuli. This finding tends to support Lenneberg's (1967) hypothesis: grammatical development of the retarded is similar to normal children, but delayed. The statistically nonsignificant difference between the mean scores of the EMR group and normal controls indicated the existence of a delayed profile in the use of grammatical morphemes.

Statistically significant differences in performance were found between the EMR and control groups on BTEM when mean scores were compared. This finding indicated a comparatively limited ability of the $E M R$ adolescent to inflect nonsense or novel stimuli when compared to control subjects of the same mental age scores. Figure 7 illustrates the differences between the performance of the experimental and control groups for production items of ICP and BTEM.

Chi-square analysis by items on the two tests, by inflection categories on the tests separately and combined further clarified the differences in gramatical performance between the control and experi- 
Experimentals

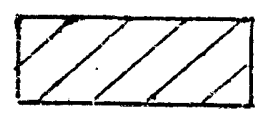

Controls

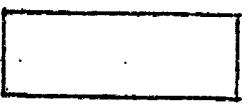

Mean Percent

Score

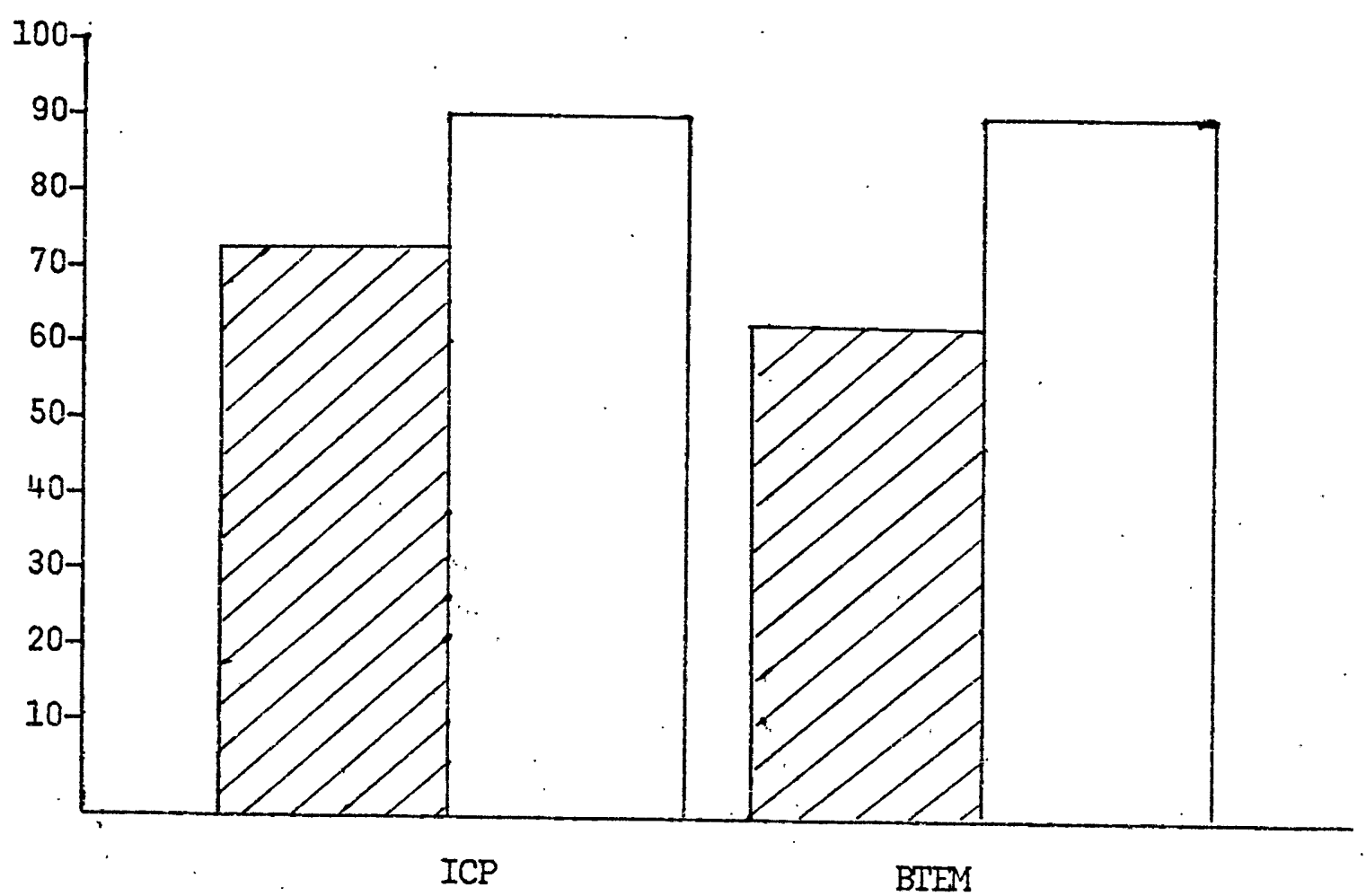

Figure 7. Differences between mean scores of Experimental and Control groups on BTEM and ICP $(N=24)$. 
mental groups. Iten analysis comparing the numbers of experimental subjects using a particular inflection correctly revealed highly significant differences on the BTEM but not on the ICP. These findings indicated that particular allomorphs of plural possessive and past tense inflections were especially difficult for EMR subjects. This significantly pocrer performance using the allomomphs for plural and possessive inflection, $\mid \partial z / /$, compared to their more successful use of $/ \mathrm{s} /$ and $/ \mathrm{z} /$, allomorphs of the same inflection, supports research by Berko (1958) and Lovell and Bradbury (1967). Berko found that regular, common allomorphs of the plural were mastered first by normal 4 to 7 year olds. Iovell and Bradbury (1967) found 14 to 15 year old educationally sub-normal subjects performed better when using regular and cormon allomorphs of Finglish inflections.

The importance of allomorphic variations in the productive control of inflections by EMR adolescents was further emphasized using chi-square analysis to compare the performance of the groups by categories of inflections on the ICP and BTEM. A highly significant difference was observed in the use of the past tense inflection. 'This indicated EMR subjects used the past tense inflection poorl.y, regardless of allomorphic variation. Statistically nonsignificant differences in the use of plural and possessive categories indicated the importance of allomorphic variation for these inflection categories.

Generally, chi-square analysis revealed the specific differences in the grammatical skill of EMR adolescents when required to inflect novel stimuli. EMR subjects demonstrated specific difficulty generating less cormon allomorphs to inflect plural and possessive and in 
generating the general morphological mule governing the inflection for past tense. These findings tend to agree with those of Loveli and Bradbury (1967) who suggested educably subnormal (ESN) subjects inflected lexicon and novel words as much by usage and memory as by the generation of rule forms. The findings of this study differ from those of Lovell and Bradbury (1967) in part since the EMR subjects in this study performed significantly poorer than normal controls only in generating rules for certain inflections to novel stimuil. These findings further support Lovell and Bradbury (1967) who stated the ESN subjects in their study made relatively little progress in inflecting lexical and novel stimuli during the school years. The EMR adolescents in this study demonstrated statistically significant differences in ability to inflect novel stimuli using less common allomorphs for plural and possessive and generally for past tense, indicating possible limitations in abstracting these forms.

Secondary to the inter-group comparisons was the question of variation of performance within groups. The statistical significance of intra-group variability was not analyzed because of the small population in this study. A common pattem of performance was observed in the control group who exhibited a smaller degree of variance in their performance on the productive items of the ICP and BTEM. The EMR group generally exhibited a greater degree of variability in their performance on the two tests.: Inspection of the data revealed common patterns of performance indicating specific difficulties in the use of English inflections by EMR adolescents. While both inter- and intra-group differences appeared to exist, a greater degree of inter- 
group difference indicated patterns of performance common to EMR adolescents which were discussed in the previous section, specific limitations in generating inflectional morphenes to novel stimuli.

A thind pant of the second question relative to the significance of intra-vs. inter-group differences was not determined.

The thind question investigated was: If a commonality exists within the retanded group, what kinds of responses are most prevalent? This question cannot be fully answered from the data provided in this study. Inspection of individual percent scores for four inflection categories on the ICP and BTEM suggested generally poorer periormance on the BTEM than on the ICP with equal performance using present progressive. The data provided in this study suggests the EMR adolescent develops grammatical mastery for inflections with few variants such as the present progressive. However, when faced with several allomorphic possibilities for inflections such as plural, possessive and past tense, he tends to form inflections using more common allomorphic forms. These patterns of perfornance may be explained by a linitation in grammatical competence in the EMR; he may not be able to generate morphological rules for inflections with several variants due to a Iinited ability to abstract less well-learned forms.

For more detailed observation of inaividual performance relative to four inflectional categonies the reader is referred to Appendix C which lists the percent scores by subject in each inflection category of the ICP and BTEM. Comparisons between the mean scores in each category showed EMR adolescents had the most difficulty using the past tense inflection on the BTEM. Other difficulties were observed in the 
use of inflections for plumal and possessive. These general observations were substantiated and clarified using chi-square analysis discussed earlier. Figure 8 illustrates the patterns of mean scores in the experimental group using four inflections on the ICP and BTEM. The findings reported in this study tend to support statements made by Menyuk (1964) and Lerneberg (1967) as well as those of other researchers (Semmel, et al., 1968) and Lovell and Bradbury (1968). Lenneberg (1967) suggested generally the developmental process in the mentally retanded is arrested in the early teens. Menyuk (1964) observed children with delayed speech were unable to move beyond the use of elementary and general grammatical miles in their speech. The developmental delay was observed in the comparable performance of EMR and normal control subjects of similar mental ages when required to inflect lexical stimuli. The comparatively poorer performance of EMR subjects using inflections with novel stimuli, specifically less common allomorphs for plural and possessive and past tense inflection generally seems to demonstrate differences beyond a developmental delay. The limitations in grammatical competence of the EMR adolescent observed in this study suggest both a quartitative delay and qualitative differences in the ability to abstract less cormon variations of granmatical morphemes. 


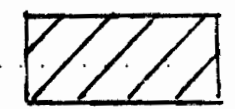

ICP

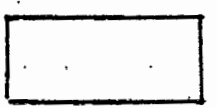

BTEM

Mean Percent

Score

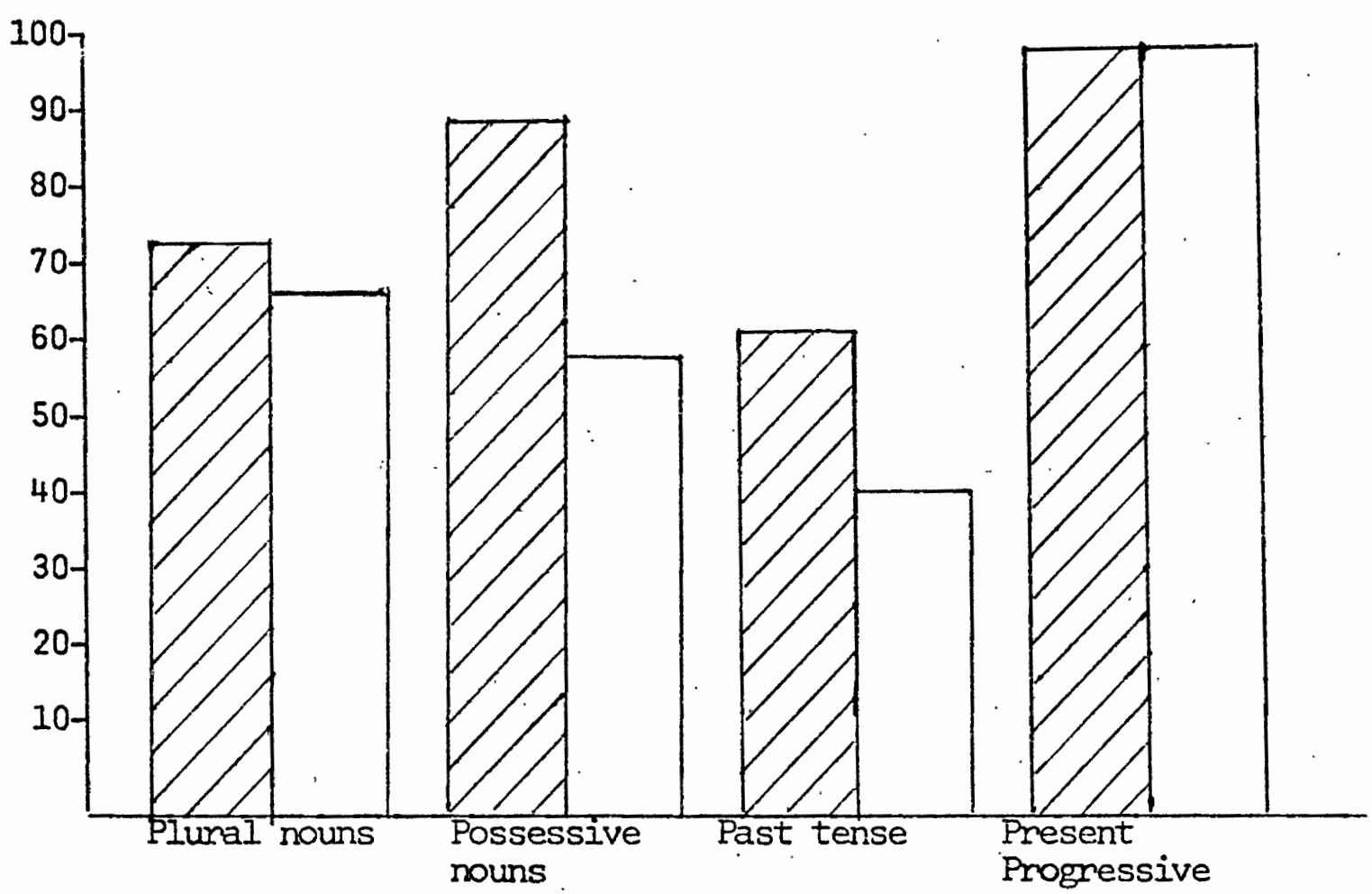

Figure 8. Mean percentage scores in four inflection categories on the ICP and BTEM for the EMR group. ( $N=12)$ 


\section{CHAPTER V \\ SUMMARY AND IMPLICATIONS}

\section{SUMMARY}

The purpose of this study was to investigate the development and use of certain grammatical morphemes, i.e., the English inflections for plural, possessive, present progressive and past tense in the speech of educable mentally retarded (EMR) adolescents. The performance on two grammatical tasks of EMR subjects was compared to that of normal control subjects matched by mental age scores. The first task was to produce, verbally, the required inflection for a novel (nonsense) word on a modified version of Berko's Test of Euglish Morphology (BTEM) (Berko, 1958). Secondly, subjects responded to grammatical contrasts in lexical or real words at levels of imitation, comprehension and production on a modified form of the Imitation, Comprehension and Production Test (ICP) (Fraser, Bellugi and Brown, 1963).

Twenty-four subjects were included in this study. Twelve EMR subjects between the ages of 15 and 20 years were randomly selected from the Vancouver School District. Twelve control subjects with normal intelizgence selected from school aged students in the PortlandVancouver area, were matched by mental age to EMR subjects. Mental age scores were determined with the Peabody Picture Vocabulary Test (Dunn, 1965. AlI subjects were screened for hearing acuity, articulation and general speech intelligibility. 
The results of this study revealed statistically significant poorer performance in the use of English inflection by EMR adolescents when compared with control-subjects of similar mental age, specifically in the use of less common allomorphs for plural, possessive and past tense.

$$
\begin{aligned}
& \text { Comparisons within each group between performance on the ICP and } \\
& \text { BTEM did not show statistically significant differences, indicating } \\
& \text { ENR adolescents as a group use inflections only slightly better in a } \\
& \text { lexical than in a novel situation. The ICP and. BIEM were thus shown to } \\
& \text { be highly similar instmments, measuring the same variables of linguis- } \\
& \text { tic performance. A lack of statistically significant differences were } \\
& \text { found in the ability of EMR adolescents to initate, comprehend or pro- } \\
& \text { duce verbally the required morpheme on the ICP. } \\
& \quad \text { No statistically significant difference was found when compar- } \\
& \text { ing the performance of the two groups on the ICP, which suggests EMR } \\
& \text { adolescents use the foum inflections investigated nearly as well in a } \\
& \text { lexical condition ds normal children of a comparable mental age. EMR } \\
& \text { subjects, however, demonstrated statistically significant poorer per- } \\
& \text { formance on the BIEM, indicating linitations in the ability to general- } \\
& \text { ize morphological mules from lexical to novel situations. Chi-square } \\
& \text { analysis showed sighificant differences between groups in the use of } \\
& \text { less common allomorphs used to inflect plural, possessive and past } \\
& \text { tense. These findings indicate EMR adolescents have specific difficul- } \\
& \text { ties using a particular allomorph, /gz/, to inflect plural and posses- } \\
& \text { sive and all allonorphs, / t/, /d/ and /ad/, in the inflection category } \\
& \text { for past tense. }
\end{aligned}
$$


Patterns of performance within groups were not established due to a limited amount of data provided by the small number of subjects in this study. When the performance of EMR subjects on the BTEM was examined, trends were suggested since all EMR subjects used the inflection for present progressive correctly. Most EMR subjects failed to use a less common allomorph for inflecting plural and possessive and nearly half did not use inflections for past tense correctly. These observations were substantiated by chi-square analysis between the EMR and control groups.

These results suggest EMR adolescents use most English inflections of the four investigated nearly as well as normal subjects with similar mental age scores in a lexical situation. The comparative difficulty of the EMR groups in generalizing morphological rules governing the use of inlections to a novel condition suggests a limited ability to abstract Iess well-learned forms to novel situations. Specific difficulty was shown by the failure of most EMR subjects to use certain less common allomorphs to inflect plural, possessive and past tense. These findings tend to support other research in this area which reports the earlier mastery of regular and common allomorphs before the less common forms. The data reported in this study suggests some qualitative differences, as well as a quantitative delay, in the use of English inflections by EMR adolescents.

\section{Implications}

\section{Clinical}

Certain strengths and weaknesses in the use of English inflection 
by EMR adolescents were suggested in this study. The use of the inflection for present progressive was consistently appropriate as was the use of the common allomorphs for inflecting plumal and possessives. A lack of competence was indicated in the use of less common allomorphs for plural, possessive and past tense. These findings suggest a need for earlier language training emphasizing the use of these grammatical morphemes for EMR students.

The non-significant differences found when comparing performance within groups on the ICP and BTEM demonstrated the high degree of similarity between the two instruments. The use of the BTEM as a diagnostic tool would appear to be a valid method of assessing grammatical competence, particularly the use of morphemes called inflections. The BTEM is a tool to be expanded, perhaps as a method of teaching the correct language patterns and certainly as a measure of learning particular language skills.

$\underline{\text { Research }}$

The small number of EMR subjects in this study, twelve, limit the extent of generalizations based on the results. In this study, EMR adolescents demonstrated a few significant differences in the use of English inflections. Primarily; ENR subjects showed difficulty with certain allomorphic variations of inflections wich pluralize, indicate possessive and past tense. The important implication of these findings is that qualitative differences may exist in EMR language in addition to general quantitative delay. Further research with larger numbers of subjects is needed to examine and to substantiate these findings. 
Additionally, the role of allomorphic variations of inflections and the ability of EMR subjects to generalize them requires extensive investigation.

Although not investigated in this study, an analysis of the grammatical performance of EMRs at levels of imitation and comprehension using novel stimuli such as on the BTEM using four inflections (plural, possessive, present progressive and past tense) may provide supplementary data regarding the apparant strengths and weaknesses reported in this study relative to verbal production.

Additional research investigating the use of other gramatical morphemes would provide data necessary to define more precisely the linguistic performance and inferred competence levels of the mildly retarded. Extending beyond the present investigation of grammatical perfomance, reseanch is needed to investigate the syntactic structure of language in the mentally retanded. A tool such as Developmental Sentence Scoring (Iee and Canter, 1971) would appear to lend itself to an analysis of language structure of EMR subjects. Research at lower levels of retardation such as the trainable level is also needed in onder to further map the nature of linguistic skills which are related to limited intellectual functioning. 
ANISFELD, Moshe and Tucker, Richard G., English pluralization rules of six-year old children. In C. M. Ferguson and D. I. Slobin (eds.), Studies of Child Language Development, San Francisco, California: HoIt, Rinehart and Winston (1973).

BERKO, Jean, The child's learning of English morphology. Word, 14, 150-177 (1958).

BERRY, Paul, Comprehension of possessive and present continuous sentences by non-retarded, mildly retanded and severely retanded children. Am. J. Yental Deficiency, 76, 540-544 (1972).

BLOOM, Lois, Language Development: Form and Function in Emenging Grammars, Res. Monogr. \#59, Cambridge, Massachusetts: MIT Press (1970).

BROWN, Roger, Imitation, Comorehension and Production Test, personal communication. (Jan., 1975).

BROWN, Roger, and Berko, Jean, Word association and the acquisition of grammar. Child Develop., 31, 1-14 (1960).

BROWN, Roger, and Fraser, Colin, The acquisition of syntax, in Ursula Bellugi and Rober Brown (eds.), The Acquisition of Language, Monogr. of the Soc. for Res. in Child Develop., 29, 9-34 (1964).

BROWN, Roger, and Bellugi, Ursula, Three processes in the child's acquisition of syntax, in Eric Lenneberg (ed.), New Directions in the Study of Language, Cambridge, Massachusetts: MIT Press, (1964).

BROWN, Roger, Social Psychology, New York: The Free Press (1965).

BROWN, Roger, A Finst Language: The Early Stages, Cambridge, Massachusetts, Harvand University Press (1973).

BROWN, Roger, and Cazden, Courtney, The child's syntax from I to III. In Ferguson and Slobin (eds.) Studies in Child Language, San Francisco: Holt, Rinehart and Winston (1973).

CARLSON, T and Carlson, L. E., Oral English errors of nomal and retanded children. Elemen. Sch. J., 45, 340-348 (1945).

CARROLL, John B., Psycholinguistics in the study of mental retardation, in R. L. Schiefelbusch, R. H. Copeland and J. O. Smith (eds.), Language and Yental Retardation, New York: Holt, Rinehart and Winston (1967). 
CARROW, Flizabeth, Assessment of speech and language in children. In J. McLean, B. E. Yoder and R. L. Schiefelbusch (eds.), Language Intervention With the Retanded, Baltimore, Maryland: University Park Press (1971).

CAZDEN, Courtney, The acquisition of noun and verb inflections. In C. M. Ferguson and D. I. Slobin (eds.), Studies in Child Language Development, San Francisco: Holt, Rinehart and Winston (1973).

CHAPMAN, Robin, Normal language and communication. In Mclean, et al., (eds.), language Intervention With the Retarded, Baltimore: University Press (1971).

CHOMSKY, Noari, Selected Readings, J. P. Allen and P. Van Buren (eds.), London: oxford University Press (1971).

DALE, Phillip S., Language Development: Structure anä Function, Hindsdale, IIlinois: Dryden Press, 1972.

DEVER, Richard B., A comparison of the results of a revised version of Berko's Test of morphology with the free speech of mentally retarded children. J. Speech Hearing Res., 15, 169-178 (1972).

DeVIILIERS, J. G. and DeVilliers, P. A., A cross-sectional study of the acquisition of grammatical morphemes in child speech. J. Psycholing. Res., 2, 331-341 (1973).

DUIN, Lloyd M., The Peabody Picture Vocabulary Test, Circle Pines, Minn.: American Guidance Service, Inc. (1965).

ERVIN-TRIPP, Susan, Language Acquisition and Commicative Choice, Stanford, California: Stanford University Press (1973).

FERGUSON, Charles M. and Slobin, Dan I., Studies in Child Ianguage Development, San Francisco: Holt, Rinehart and Winston (1973).

FOLEY, Helen M. and Locke, J. L., Young children's knowledge of morphological and phonological rules. J. Cormun. Dis., 4, 259-262 (1971).

FRASER, Colin, Bellugi, Ursula and Brown, Roger, Control of grammar in imitation, comprehension and production. J. Verbal Leam. Verbal Behav., 2, 121-135 (1963).

HAAS, W. A. and Haas, S. K., Syntactic structure and language development in retardates. In R. L. Schiefelbusch (ed.) Language of the Retarded, Baltimore: University Park Press (1972).

HOPPER, R. and Naremore, R. C., Children's Speech, New York: Harper and Row (1973). 
JORDAN, Thomas, Perspectives in Mental Retardatjon, Carbondale, IIlinois: Southem IIlinois University Press (1966).

JORDAN, Thomas, Language and mental retardation: A review of the literature. In R. L. Schiefelbusch, et al., (eds.), Language and Mental Retardation, New York: Holt, Rinehart and Winston (1967).

KARLIN, I. W. and Strazzula, M., Speech and language problems of mentally retarded children. J. Speech Hearing Dis., 17, 286-294 (1952)

KEANE, Vincent E., The incidence of speech and language problems in the mentally retarded, Mental Retardation, 10, 3-5, (1972).

KUTMA, Edward and Bellugi, Unsula, Syntactic regularities in children's speech. In J. Lyons and R. Wales (eds.), Psycholinguistic Papers. Edinburgh University Press (1966).

LANGAKER, Ronald W., Language and its Structure, San Francisco: Harcourt, Brace and World (1968).

IEE, Laura L. and Canter, Susan M., Developmental sentence scoring: A clinical procedure for estimating syntactic development in children's spontaneous speech. J. Speech Hearing Dis., 36, 315-341 (1971).

LENNEBERG, Eric, Nichols, I., and Rosenberger, E., Primitive stages of languave development in mongolism. Dis. Commun., 42, 119-137 (1964).

IFNNEBERG, Enic, The Biological Bases of Language, New York: Wiley and Sons (1967).

LOVEIL, K. and Bradbury, B., The learning of english morphology in educationally subnormal special school children. Am. J. Mental Deficiency, 71, 608-615 (1967).

LOVELL, K. and Dixon, E., The growth and control of gramar in imitation, comprehension and production. Child Psychol. Psychiat., 8, 31-39 (1967).

LOZAR, B. and Wepman, Joseph; Lexical usage of mentally retarded and non-retarded children. Am. J. Mental Deficiency, 76, 534-559 (1972)

MATTHEWS, Jack, Speech problems of the mentally retarded. In Lee Travis, (ed.), Handbook of Speech Pathology, New York: AppletonCentury-Crofts (1957).

MENYIK, Paula, Comparison of grammar of children with functionally deviant and normal speech. J. Speech Hearing Res., 7, 109-121 (1964). 
MENYUK, Paula, Sentences Children Use, Cambridge: MIT Press (1969).

MENYUK, Paula, The Acquisition and Development of Language, Englewood Cliffs, New Jersey: Prentice Hall (1971).

McNEILL, David, The creation of language by children. In L. Lyons and R. J. Wales (eds.), Psycholinguistic Papers, Edinburgh: Edinburgh University Press $(1966)$.

McNEILL, David, The capacity for ontogenesis of grammar. In D. I. Slobin (ed.), The Ontogenesis of Grammar, New York: Academic Press (1971).

MILLER, Wick and Ervin, Susan, The development of gramnar in child language. In Bellugi and Brown (eds.), The Acquisition of Language, Monographs of the Society for Research in Child Development. 29, 9-34 (1964).

NEWFIEID, M. and Schlanger, B., The acquisition of English morphology by normal and educable mentally retarded children. J. Speech Hearing Res., 11, 693-706 (1968).

NIDA, Eugene A., Morphology, The Descriptive Analysis of Words, Ann Arbor: The University of Michigan Press (1961).

OLSON, David R., Language acquisition and cognitive development. In $H$. Carl Haymood (ed.), Social-Cultural Aspects of Mental Retardation, New York: Appleton-Century-Crofts (1970).

PAPANIA, Neil, A qualitative analysis of vocabulary responses of institutionalized mentally retarded children. J. Clinical Psychol., 10, 361-365 (1954).

ROSENBERG, Sheldon, Problems of language development in the retarded. In H. C. Haywood (ed.), Social-Cultural Aspects of Mental Retardation, Appleton-Century-Crofts (1970).

RUDER, Kenneth, A psycholinguistic viewpoint of the language acquisition process. In R. L. Schiefelbusch (ed.), Language of the Retarded, Baltimore: University Park Press (1972).

SCHLANGER, B., Speech examination of institutionalized mentally handicapped children. J. Speech Hearing Dis., 18, 339-349 (1953).

SEIGAL, Gerald M., Three approaches to speech retandation. In R. L. Schiefelbusch (ed.), Language of the Retarded, Baltimore: University Park Press (1972).

SEMIEL, M., Lefson, M., and Sitko, M., Learning and transfer of paradigmatic word association by educable mentally retarded children: A preliminary report. Studies Lang./Lang. Behav., 5, 343-363 (1967). 
SEMMI, M., Barritt and Penfetti, A grammatical analysis of word associations of educable mentally retarded and nomal children. Am. J. Mental Deficiency, 72, 567-576 (1968).

SLOBIN, Dan I., Psycholinguistics, Glenview, Illinois: Scott, Foresman and Company (1971).

SIITH, James $0 .$, Speech and Ianguage of the retarded. In Jerome Rothstein (ed.), Mental Retardation. San Francisco: Holt, Rinehart and Winston (1971).

SPRADIIN, L. E., Language and communication of mental defectives. In N. R. Ellis (ed.), Handbook of Mental Deficiency, New York: McGraw-Hill (1963).

WARDHAUGH, Ronald, Introduction to Linguistics, New York: McGraw-Hill (1972).

WIIG, Elizabeth, Semmel, M., and Crouse, M. B., The use of English morphology by high risk and leaming disabled children. J. Learning Dis., 6, 457-465 (1973).

YODER, D., and Miller, J. F., What we know and what we may do. In Mclean, et al. (eds.), Language Intervention with the Retarded, Baltimore: University Press (I971). 


\section{APPENDIX A \\ IMITATION COMPREHENSION PRODUCTION}

INSTRUCTIONS

COMPREHENSION

"Here are two pictures. I'm going to tell you what they are called; and then you show me the one I ask for. One is called . . and one is called... Show me (underlined phrase). Show me (the other one)."

And: "Here are two more pictures. One is . . and one is ... Show me . ." (etc.)

\section{MODELS}

"I'm going to show you two pictures. I'Il tell you the names of the pictures and you tell me the one I point to. One picture is ... . and one picture is . . I'll say them again. (Reverse order this time). One is . . and one is . What is this one, called? (point to underlined one). What is this one called? (point to other one)."

And: "Here are two more pictures. One is . ." (etc.)

\section{IMITATION}

"I'm going to say two things and then I want you to say them. $I^{\prime} m^{\text {' }}$ going to say . . and . . Now you say . . (underlined one). Now you say .. (the other one)." etc. 
IMITATION, COMPREHENSION AND PRODUCTION TEST

(Modified Vension)

PRODUCTION:

Training item--The cat with the brown face. The dog with the black tail.

1a. "The boys draw.

Ib. The boy draws.

2a. The girls' horses.

2b. *The girl's horse.

3a. The match burned.

3b. *The match is burning.

4a. The dog digs.

4b. *The dogs dig.

5a. *The monny cleared.

5b. The momy is cleaning.

6a. The boys' boats.

6b. *The boy's boat. 7a. *The boy is jumping.

7b. The boy jumped.

8a. *The kittens play.

8b. The kitten plays.

9a. The girl's dog.

9b. *The girls' dogs.

10a. The paint spilled.

10b. EThe paint is spilling.

11a. *The girls wave.

11b. The girl waves.

12a. The boys' wagons.

$12 \mathrm{~b}$. 'The boy's wagon.

\section{IMTTATION:}

13a. The boy is kicking.

13b. *The boy kicked.

14a. *The boy eats.

14b The boys eat. 15a. *The girls' cats.

15b. The girl's cat.

16a. *The man is working.

16b. The man worked.

\section{COMPREHENSION:}

Training item--The boy playing with the truck. The mouse eating the cracker.

17a. The baby is pounding.

17b. *The baby pounded.

18a. *The girls reads. 18b The girls read. 19a. The boys' toys.

19b. "The boy's toy.

20a. The dogs play:

20b. :The dog plays. 
BERKO:S TEST OF ENGLISH MORPHOLOGY

(Modified Version)

Training items:

a. This is a glass.

Now there are two of them.

There are two. $. / 2 z /$

b. This is an ice cube.

It is melting.

Now is is all gone. It .lad /

1. This is a wug.

What is this?

Now there are two .$|z|$

8. This man knows how to mot. He is .$/ \eta^{\prime}$

9. This is a lun.

What is this?

Here are two $. / z /$

What is he doing?

He did the same thing yesterday.

Yestenday, he $. / d /$

3. This is a kahz.

What is this?

Now there are two .$|a z|$

4. This man is ricking.

What is he doing?

He did it yestenday, too.

Yesterday, he $. / t /$

10. This man is bodding. He did it yestenday, too. Yestenday, he .lad/

11. This is a heaf. What is this?

Now there are two $. / \mathrm{s} / \mathrm{or} / \mathrm{vz} /$

12a. This is a bik. He owns a hat. Whose hat is this?

The ./s/

6. This is a tor.

What is this?

These are two $. / z /$

12b. Here are two biks. They own hats too. Whose hats are these? The $. / \mathrm{s} /$

7a. This is a niz.

He owns a hat.

Whose hat is this?

The $|a z|$.

7b. Here are two nizzes.

They own hats too.

Whose hats are these?

The $\mid a z /$. 
APPENDIX B

PERCENTAGES FOR EMR SUBJECTS ON THE ICP AND BTEM $(N=12)$

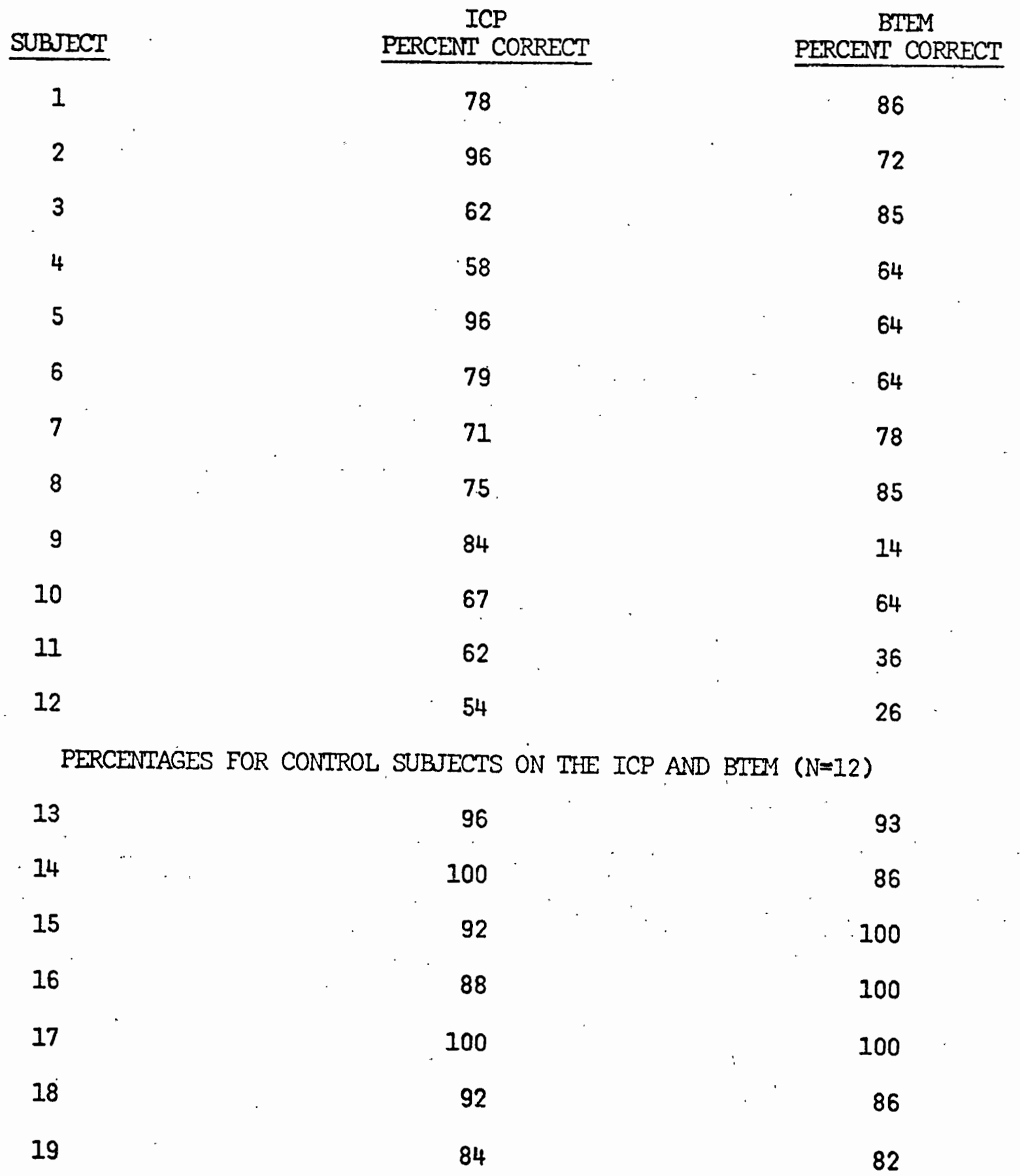


SUBJECT

20

21

22

23

24
ICP

PERCENT CORRECT

84

71

92

92

96

75

BTEM

PERCENT CORRECT

100

72

100

93

86 


\section{APPENDIX C}

PERCENTAGES OF CORRECT RESPONSES FOR EMR GROUP ON PRODUCTION ITEMS OF ICP $(N=12)$ AND BTEM

\begin{tabular}{|c|c|c|c|c|c|c|c|c|}
\hline \multirow[t]{2}{*}{ SUBJECT } & \multicolumn{2}{|c|}{ PLURAL } & \multicolumn{2}{|c|}{ FOSSESSIVE } & \multicolumn{2}{|c|}{ PAST TENSE } & \multicolumn{2}{|c|}{$\begin{array}{c}\text { PRESENT } \\
\text { PROGRESSIVE }\end{array}$} \\
\hline & ICP & BTEM & $I C P$ & BTEM & ICP & BTEM & ICP & BTEM \\
\hline 1 & 100 & 80 & 100 & 75 & 80 & 0 & 100 & 100 \\
\hline 2 & 100 & 60 & 87 & 50 & 100 & 100 & 100 & 100 \\
\hline 3 & 83 & 20 & 100 & 25 & 100 & 0 & 80 & 0 \\
\hline 4 & 100 & 100 & 100 & 75 & 75 & 66 & 75 & 100 \\
\hline 5 & 100 & 80 & 87 & 50 & 75 & 33 & 50 & 100 \\
\hline 6 & 66 & 80 & 62 & 100 & 25 & 66 & 100 & 100 \\
\hline 7 & 66 & 80 & 100 & 75 & 50 & 66 & 100 & 100 \\
\hline 8 & 33 & 80 & 100 & 50 & 25 & 33 & 100 & 100 \\
\hline 9 & 66 & 80 & 50 & 75 & 50 & 66 & 25 & 100 \\
\hline 10 & 50 & 60 & 100 & 50 & 50 & 0 & 100 & 0 \\
\hline 11 & 50 & 60. & 100 & 50 & 50 & 66 & 75 & 100 \\
\hline 12 & 33 & 20 & 75 & 0 & 50 & 0 & 100 & 100 \\
\hline
\end{tabular}

